OPEN ACCESS

Edited by:

Jurgen Germann,

University Health Network

(UHN), Canada

Reviewed by:

Timothy Brown,

The University of Manchester,

United Kingdom

llia N. Karatsoreos,

University of Massachusetts Amherst,

United States

*Correspondence:

Hugh D. Piggins

hugh.piggins@bristol.ac.uk

Specialty section:

This article was submitted to

Pathological Conditions,

a section of the journal

Frontiers in Behavioral Neuroscience

Received: 15 November 2021

Accepted: 27 December 2021

Published: 28 January 2022

Citation:

Young CJ, Lyons D and Piggins HD

(2022) Circadian Influences on the

Habenula and Their Potential

Contribution to Neuropsychiatric

Disorders.

Front. Behav. Neurosci. 15:815700.

doi: 10.3389/fnbeh.2021.815700

\section{Circadian Influences on the Habenula and Their Potential Contribution to Neuropsychiatric Disorders}

\author{
Callum J. Young, David Lyons and Hugh D. Piggins* \\ School of Physiology, Pharmacology, and Neuroscience, University of Bristol, Bristol, United Kingdom
}

The neural circadian system consists of the master circadian clock in the hypothalamic suprachiasmatic nuclei (SCN) communicating time of day cues to the rest of the body including other brain areas that also rhythmically express circadian clock genes. Over the past 16 years, evidence has emerged to indicate that the habenula of the epithalamus is a candidate extra-SCN circadian oscillator. When isolated from the SCN, the habenula sustains rhythms in clock gene expression and neuronal activity, with the lateral habenula expressing more robust rhythms than the adjacent medial habenula. The lateral habenula is responsive to putative SCN output factors as well as light information conveyed to the perihabenula area. Neuronal activity in the lateral habenula is altered in depression and intriguingly disruptions in circadian rhythms can elevate risk of developing mental health disorders including depression. In this review, we will principally focus on how circadian and light signals affect the lateral habenula and evaluate the possibility that alteration in these influences contribute to mental health disorders.

Keywords: circadian, depression, clock gene, burst firing, epithalamus

\section{INTRODUCTION}

It takes a mere cursory glance at social media to deduce that the mental-health conversation is as critical today as it has ever been. We live in a world where the public feel that mental illness remains an unsolved dilemma. They express dissatisfaction with their acute and long-term suffering, as well as the pharmacotherapies available to alleviate this (Priest et al., 1996; Hergerl et al., 2003; Partridge et al., 2012; Horowitz and Graf, 2019). Exemplifying this discontent, depression is a mood disorder characterised by persistent low mood and anhedonia (Tolles-Correia et al., 2018). This mental illness is the leading cause of disability globally (Charlson et al., 2019) and affects over 264 million people (GBD 2017 Disease Injury Incidence Prevalence Collaborators, 2018). Despite this, a universally effective treatment for depression is unavailable, and approximately one third of patients fail to respond to conventional antidepressant drugs (Corriger and Pickering, 2019). Moreover, there is an absence of consensus on how to define depression (Tolles-Correia et al., 2018), making its diagnosis and treatment one of the greatest challenges in modern psychiatry.

As such, a surge of neuroscience research continues to dissect the pathophysiology that underpins depression. At the turn of the previous decade, the brain's epithalamus was identified as a potential new therapeutic target for treatment resistant depression. Specifically, deep brain stimulation (DBS) of the lateral habenula ( $\mathrm{LHb}$ ) was shown to alleviate depressive symptoms in a therapy-refractive patient (Sartorius et al., 2010). Further, when DBS was discontinued, there was an immediate and profound relapse of these depressive symptoms. This highlights the potential importance of the epithalamus in mood regulation (Shabel et al., 2014). 
The LHb is an evolutionarily conserved epithalamic structure (Bianco and Wilson, 2009; Hikosaka, 2010), most investigated for its role as an "anti-reward" centre (Shabel et al., 2012) with anatomical connections allowing it to exert inhibitory control over midbrain monoaminergic centres ( $\mathrm{Hu}$ et al., 2020). In part, it is these network connections which make the LHb an interesting candidate for depression research (Sartorius and Henn, 2007). Recently, rodent studies have further implicated the epithalamus in depression ( $\mathrm{Hu}$ et al., 2020). More specifically, elevated neural activity in the rodent LHb has been associated with various depression models including learned helplessness (Li et al., 2011; Cui et al., 2018), chronic stress (Cerniauskas et al., 2019) and chronic pain (Zhuo et al., 2019). A landmark paper has also implicated the LHb in the antidepressant mechanism of ketamine (Yang et al., 2018a), although this utilised supraclinical doses. In addition, human fMRI studies show differing $\mathrm{LHb}$ activity, and functional connectivity, between depressed and healthy individuals (Lawson et al., 2017; Zhu et al., 2019; RivasGarajales et al., 2021). From this evidence, it is implied that the $\mathrm{LHb}$ is an epicentre for depression's mechanistic underpinnings.

In addition to this, the $\mathrm{LHb}$ is situated within an extended neural circadian circuit (Bano-Otalora and Piggins, 2017). Immunohistochemical evidence indicates that the rodent $\mathrm{LHb}$ receives regulation from the master circadian pacemaker in the suprachiasmatic nucleus (SCN; Hastings et al., 2018). Further, the $\mathrm{LHb}$ receives input from other hypothalamic circadian oscillators (Guilding and Piggins, 2007; Guilding et al., 2009; Poller et al., 2013; Stamatkis et al., 2016) and the retina (Qu et al., 1996). Indeed, rodent $\mathrm{LHb}$ neurones show diurnal variation in their electrophysiological properties and are responsive to retinal illumination (Zhao and Rusak, 2005; Sakhi et al., 2014b).

Interestingly, circadian disruptions are commonly reported in patients suffering from depression (Jagannath et al., 2013; Difrancesco et al., 2019). Moreover, the efficacy of certain antidepressant therapies has been hypothesised to be time of day dependent (Swanson et al., 2017). Given its endogenous circadian properties, and neural connections with brain structures associated with circadian timing and mood, the LHb is a likely candidate as a locus of interaction between depression and circadian disruptions. In this review, we evaluate the current state of understanding regarding the LHb's anatomical and molecular organisation, and its functional involvement in the pathology of depression. We also consider the intrinsic and extrinsic factors shaping the daily variation in this structure's properties, and explore the potential links between circadian rhythms, depression, and the LHb.

\section{ORGANISATION OF THE HABENULA COMPLEX}

The habenula is a cellularly diverse structure located in the posterior-dorsal-medial region of the thalamus (Hu et al., 2020) and can be divided into anatomically distinct lateral and medial nuclei [the LHb and the medial habenula (MHb); Diaz et al., 2011]. The LHb and MHb differ in their afferent and efferent connections (Aizawa et al., 2011, 2012) and play largely different roles in their respective neural circuits. Unlike the predominantly glutamatergic $\mathrm{LHb}$, the $\mathrm{MHb}$ contains substance $\mathrm{P}$ expressing neurones and cholinergic cells in its dorsal and ventral division, respectively (Aizawa et al., 2012). Although both structures are becoming increasingly implicated in the pathophysiology of various psychiatric conditions (Metzger et al., 2021), the nature of these differ. The MHb is predominantly implicated in nicotine withdrawal (Fowler et al., 2011; Hsu et al., 2013), drug addiction (Glick et al., 2006; Lopez et al., 2018) and anxiety (Zhang et al., 2016), while functional studies suggest that aberrant LHb activity is more closely associated with depression (Li et al., 2013; Seo et al., 2018; Yang et al., 2018b). However, recent research has highlighted an increasingly complex role for the $\mathrm{LHb}$ in various reward pathologies, including drug seeking (Li et al., 2017; Nair et al., 2021).

The LHb shows considerable intranuclear heterogeneity in morphology and cytochemistry (Diaz et al., 2011; Hu et al., 2020). As such, it can be subdivided into medial and lateral divisions (LHbM and LHbL; Aizawa et al., 2012) and further apportioned into nine subnuclei based on immunocytochemical, topographical, and morphological criteria (Figure 1; Wagner et al., 2014). Subsequent transcriptomic profiling suggests though that LHb cell types are heterogeneous and do not map closely with these subnuclear boundaries (Wagner et al., 2016). Instead, topographically and transcriptionally distinct cell clusters have been identified as a more useful approach to divide the LHb (Hashikawa et al., 2020). Not only does this approach provide a more accurate reflection of cell type-distribution, but these transcriptionally distinct neurones are differentially recruited by aversive stimuli (Cerniauskas et al., 2019), illustrating a heterogeneous response to stress within the LHb.

As well as defining $\mathrm{LHb}$ cell types according to their transcriptome, neurones can be distinguished by their mode of firing (Weiss and Veh, 2011; Sakhi et al., 2014b). Three modes of firing have been identified in the LHb: silent, tonic firing, and burst firing (Yang et al., 2018a). Another study distinguished between depolarised and hyperpolarised silent states and described an additional bistable state in which neurones oscillate between firing and quiescence (Sakhi et al., 2014b). Cells exhibiting different firing modes have different resting membrane potentials (RMP), with bursting neurones more hyperpolarised than their tonic, silent, and bistable counterparts. Firing mode is not dependent on cellular morphology or subnuclear location, but is acutely sensitive to perturbations in membrane potential (Kim and Chang, 2005; Weiss and Veh, 2011). Indeed, LHb neurones show extensive firing mode plasticity, with depolarising stimuli driving a shift in firing mode from burst to tonic firing (Cui et al., 2018), and injections of negative current causing rebound bursts (Kim and Chang, 2005; Yang et al., 2018a).

The necessity for hyperpolarisation in burst firing neurones is explained by two principal bursting mechanisms in the LHb (Yang et al., 2018a). The first-requiring the most pronounced hyperpolarisation-is cell autonomous and driven by sequential recruitment of intrinsic ionic conductances. These are hyperpolarisation-activated cyclic nucleotide-gated channels and T-type calcium channels (TTCCs), which are activated 


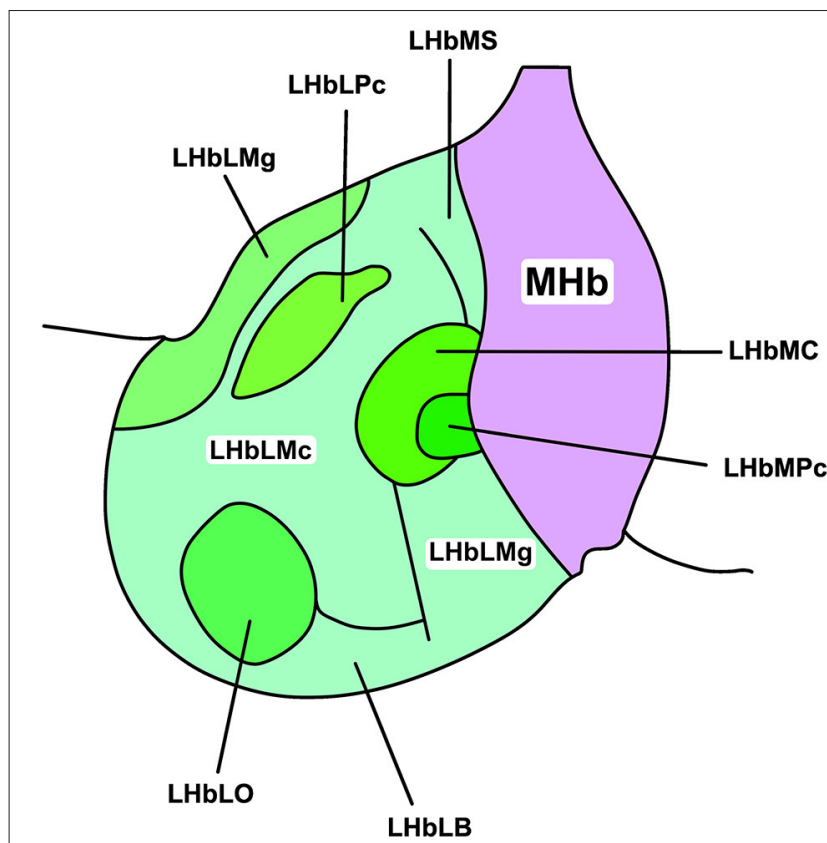

FIGURE 1 | Subnuclear organisation of the rat LHb. The habenular complex can be divided into lateral and medial subdivisions ( $\mathrm{LHb}$ and $\mathrm{MHb}$, respectively). The LHb can be further divided into medial and lateral regions ( $\mathrm{LHbL}$ and LHbM, respectively), and thus into nine cytochemically, topographically, and morphologically distinct subnuclei. These include, in the LHbL: the marginal subnucleus of the LHbL (LHbLMg), the magnocellular subnucleus of the LHbL (LHbLMc), the oval subnucleus of the LHbL (LHbLO), the basal subnucleus of the LHbL (LHbLB), and the parvocellular subnucleus of the LHbL (LHbLPc). In the LHbM: the superior subnucleus of the LHbM (LHbMS), the central subnucleus of the LHbM (LHbMC), the parvocellular subnucleus of the LHbM ( $\mathrm{LHbMPc}$ ), and the marginal subnucleus of the LHbM (LHbMMg). Redrawn and adapted from Wagner et al. (2014).

and de-inactivated by membrane hyperpolarisation, respectively. The second occurs within a specific membrane potential range ( -55 to $-65 \mathrm{mV}$ ), and is network dependent, utilising the interplay between NMDA receptors and TTCCs. Understanding the electrophysiological mechanisms underpinning burst firing is critical to elucidating the function of this activity profile (Figure 2).

As well as these firing modes, LHb function is characterised by its status as a highly interconnected relay structure mediating communication between the limbic forebrain and midbrain (Figure 3; Herkenham and Nauta, 1977, 1979; Sutherland, 1982). Most simplistically, the LHb recieves input from the hypothalamus and basal forebrain, integrates these signals, and exerts inhibitory control on monoaminergic centres in the midbrain. In reality, the nature of this connectivity is more complex, and is subject to extensive regulation. Potentially, the most influential factors driving daily variation in the $\mathrm{LHb}$ arises from its afferent connectivity with the SCN (Buijs, 1978; Zhang et al., 2009; Bano-Otalora and Piggins, 2017), the paraventricular nuclei (PVN; Hernandez et al., 2015), the dorsomedial hypothalamus (DMH; Ter Horst and Luiten, 1986; Morin, 2013), the lateral hypothalamic area (LH; Poller et al., 2013; Stamatkis et al., 2016) and the retina (Qu et al., 1996).
Moreover, reciprocal connections with the Globus pallidus internus (GPi; Entopenduncular nucleus/EP in rodents; Shabel et al., 2012), ventral tegmental area (VTA; Omelchenko et al., 2009; Cerniauskas et al., 2019), the dorsal and medial raphe (DR, MR; Lima et al., 2017; Szonyi et al., 2019), and the rostromedial tegmental area (RMTg; Laurent et al., 2017; Tooley et al., 2018) are critical for the LHb to exert its role in the aetiology of depression. These connections will be explored more fully throughout this article (for a full review of LHb network connections, please see $\mathrm{Hu}$ et al., 2020).

\section{INTRINSIC REGULATION OF LATERAL HABENULA CIRCADIAN ACTIVITY}

Expression of the immediate early gene $c$-fos is conventionally used as a proxy for neuronal activity, and immunohistochemical detection of c-Fos protein facilitates assessment of such activity ex vivo (He et al., 2019). This tool is useful when determining if neuronal activity shows circadian variation and associating this with an animal's active behavioural state. In the rodent LHbM, c-Fos immunoreactivity (-ir) is positively correlated with activity levels, showing elevation during the behaviourally active night (Paul et al., 2011).

The potential explanations for this observation are myriad. It could mean that $\mathrm{LHbM}$ activity responds to behavioural feedback, that increased late day/nocturnal activity in the LHbM is regulated by the same networks which drive these temporal behavioural patterns, or that the LHbM possesses its own intrinsic rhythmicity. In support of the latter of these hypotheses, ex vivo electrophysiological studies revealed sustained daynight/circadian variation of neuronal activity in rodent $\mathrm{LHb}$ brain slices (Zhao and Rusak, 2005; Sakhi et al., 2014b). Since these LHb explants are isolated from extra-habenular circadian input, this suggests that these $24 \mathrm{~h}$ oscillations in $\mathrm{LHb}$ neurones are, at least in part, intrinsically generated.

In the SCN, and other circadian oscillators, intrinsic rhythmicity is generated by a "molecular clock." This molecular clock is driven by a series of transcription/translation feedback loops (TTFL), featuring "clock genes" which encode transcription factors controlling the expression of highly diverse gene suites (for full review see Partch et al., 2014). The protein products of four integral clock genes drive the core TTFL: two activators (CLOCK and BMAL1) and two repressors (PER and CRY). Two homologues of Per (Per1 and Per2) and Cry (Cry1 and Cry2) exist and exhibit different distributions of expression across the mammalian brain (Shieh, 2003; Christiansen et al., 2016), and specifically within the habenula complex (Olejniczak et al., 2021).

Due to the rhythmic pattern of their expression, and their role in generating cell intrinsic rhythmicity, these clock genes can be used to investigate the independence of $\mathrm{LHb}$ oscillations. If, in ex vivo LHb explants, clock genes continue to show rhythmic expression then it suggests that oscillations in LHb activity undergo intrinsic regulation via the molecular clock. Assessments of clock gene expression, measuring bioluminescence from the PER2:Luciferase reporter construct, showed the maintenance of rhythmicity for up to 


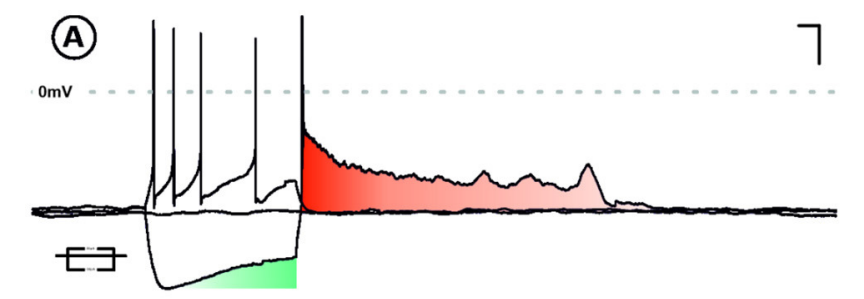

(B)

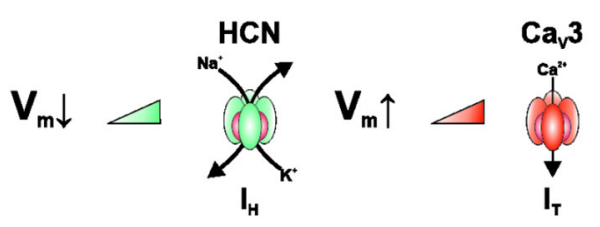

(C)

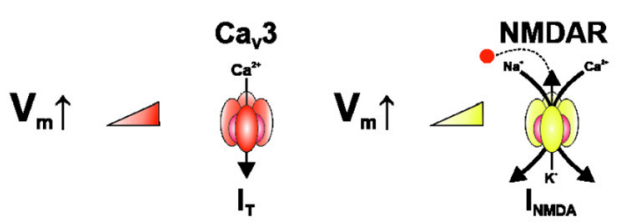

(Ai)

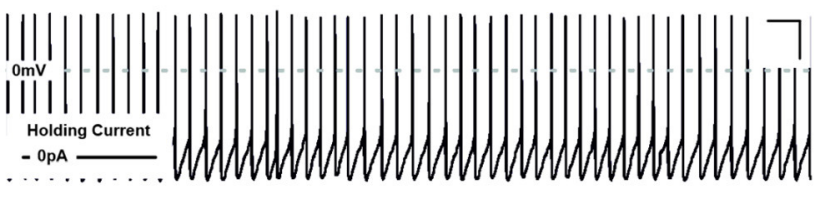

(Bi)

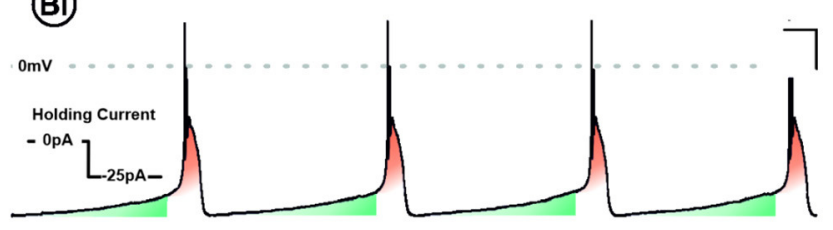

(Ci)

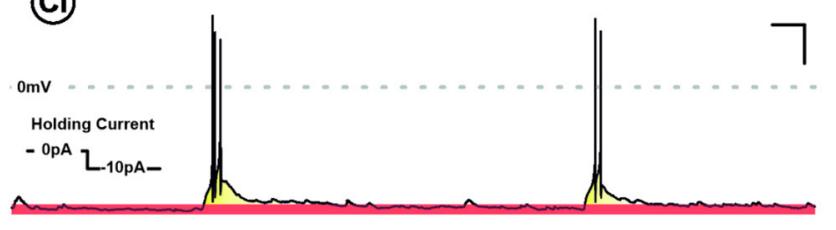

FIGURE 2 | lonic mechanisms underpinning burst firing in the LHb. (A) Voltage response of a LHb neurone to negative and positive square form current injection. Note the depolarising sag (blue) and subsequent rebound excitation (red). In addition to tonic discharge patterns (Ai), LHb neurones are capable of two mechanistically distinct modes of burst firing. Both require membrane hyperpolarisation and are characterised by rhythmic periods of depolarisation, capped by high frequency action potentials. One mechanism, requiring more pronounced depolarisation, is cell autonomous and recurrent (B). This cycle relies on the sequential activation and de-inactivation of hyperpolarisation-activated cyclic nucleotide-gated channels (HCN-blue) and T-type calcium channels (Cav3-red), respectively (Bi). The other is network dependent (C) and occurs within a specific membrane potential range ( -55 to $-65 \mathrm{mv})$. This depends on the interplay between Cav 3 and NMDA receptors (NMDARs - Yellow). Activation of T-type removes $\mathrm{Mg}^{2+}$-dependent blockade of NMDARs, synergistically driving a burst of action potentials. With membrane potential repolarisation Cav3 channels de-inactivate permitting the cycle to begin again $(\mathbf{C i})$.

$48-72 \mathrm{~h}$ in the ex vivo LHb brain slice (Guilding et al., 2010, 2013), while less robust, low amplitude rhythms are visualised in the adjacent $\mathrm{MHb}$. Rhythms in PER2::LUC were most prominent in the LHbM, with a less distinctive signal detected in the LHbL. Similar to the SCN, the period of PER2::LUC rhythms in the LHb is elongated by the Afterhours mutation (Guilding et al., 2013), indicating that the molecular basis of circadian oscillations is conserved between the SCN and LHb. Indeed, Per1:Luciferase oscillations in the LHb explant are also observed (Sakhi et al., 2014b) and are lost in LHb slices from mice lacking a functional molecular clock.

There are some inconsistencies in the reporting of habenular clock gene expression, likely due to different approaches and experimental settings. When measured using in-situ hybridisation, Per1 and Per2 expression was observed to be more prominent in the MHb than the LHb (Olejniczak et al., 2021), while an earlier study suggested that clock gene expression was absent from the LHb (Shieh, 2003). Since Olejiniczak and colleagues combined regional markers in conjunction with real time PCR, when measuring Per1 and Per 2 expression in the LHb, the most parsimonious conclusion is that expression of clock genes in the LHb is at a low level and may be localised to the $\mathrm{LHbM}$ which is adjacent to the lateral border of the MHb.
Daily changes in neurophysiological activity of LHb explants are also abrogated in $C r y 1^{-/-} \mathrm{Cry} 2^{-/-}$mice (Sakhi et al., 2014b). Since these mice do not have functional molecular clocks, the most likely explanation is that daily functional variation in LHb neuronal activity arises from intrinsic regulation by clock genes. However, it is also possible that other epithalamic/thalamic structures can entrain LHb activity and that it is the absence of rhythmic clock gene expression in these structures that underpins the loss in daily fluctuations in LHb neuronal activity. Interestingly, similar ablations of neural oscillations occur in the MHb of $\mathrm{Cry}^{-/-} \mathrm{Cry} 2^{-/-}$mice (Sakhi et al., 2014a). It is therefore possible that functional circadian variations in the $\mathrm{LHb}$ are dependent on information flow from the MHb. Such an intrahabenular circadian circuit is evidenced by the existence of a unidirectional projection from the MHb to $\mathrm{LHb}$ (Kim and Chang, 2005), but the relevance of this requires further study.

\section{EXTRINSIC REGULATION OF LATERAL HABENULA CIRCADIAN ACTIVITY}

As well as manifesting intrinsic regulation, via the molecular clock, the LHb sits within a diffuse neural circadian network 


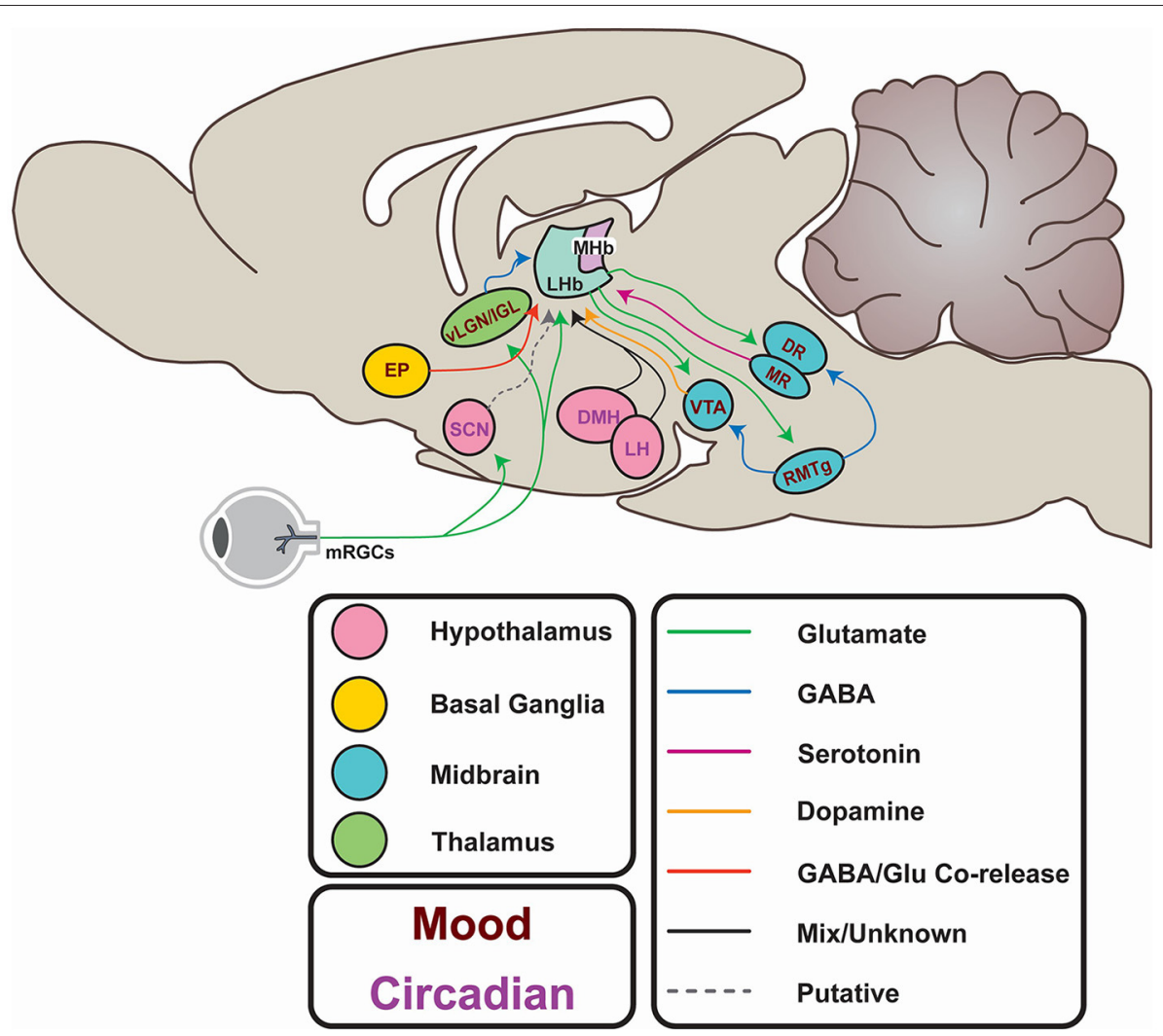

FIGURE 3 | Afferents and efferents of the LHb. From the hypothalamus, the lateral hypothalamic area (LH) and dorsomedial hypothalamus (DMH) potentially entrain the LHb to circadian rhythms. These areas receive input from the suprachiasmatic nucleus (SCN), which in turn may entrain the LHb, either directly (via putative Prokineticin 2-containing efferents) or indirectly via SCN innervation of the $\mathrm{LH}$ and DMH. The SCN itself is entrained to the external light-dark cycle through photic information directly conveyed by non-image forming retinal projections. Similar projections from melanopsin-expressing retinal ganglion cells (mRGCs) terminate in areas immediately adjacent to the LHb. Additionally, the LHb may receive photic information via the ventral lateral geniculate or Intergeniculate nucleus (vIGN/IGL). Input from the entopeduncular nucleus (EP) encodes anti-reward, and activity in this pathway is elevated in depression. Excitatory projections to the rostromedial tegmental area (RMTg) provides feedforward inhibition to the ventral tegmental area (VTA) and the raphe nuclei (DR and MR) which regulates mood and reward learning. The VTA provides reciprocal GABAergic projections to the LHb to provide feedback inhibition and encode reward. The DR provides serotonergic projections which inhibit excitatory innervation of the LHb from the EP, and itself generates excitatory postsynaptic currents.

featuring the SCN and various secondary oscillators (BanoOtalora and Piggins, 2017). A large body of evidence suggests that the $\mathrm{LHb}$ receives either direct or indirect regulation from these timekeeping components. The presence of AVP-ir terminals in the $\mathrm{LHb}$ provides evidence for a putative projection from the $\mathrm{SCN}$, as this neuropeptide is a highly expressed output molecule for the master clock (Buijs, 1978; Cagampang et al., 1994). Similarly, prokineticin 2 (PK2) projections from the SCN terminate in the LHb (Zhang et al., 2009); the LHb expresses the PK2 receptor (Zhou and Cheng, 2005), and PK2 evokes gabazine sensitive inhibitory currents to inhibit LHb neurones (Sakhi et al., 2014b). However, this PK2 projection is yet to be independently replicated, and AVP terminals in the LHb have since been traced to magnocellular neurones in the PVN (Hernandez et al., 2015). As such, the question of whether the SCN directly projects to LHb remains unresolved.

Nonetheless, the LHb likely receives indirect regulation from the SCN via other oscillators in the forebrain, thalamus and brainstem (Morin, 2013). For example, the SCN directly innervates the DMH and $\mathrm{LH}$, which both show daily changes in neuronal activity (Marston et al., 2008; Guilding et al., 2009), and innervate the LHb (Poller et al., 2013; Stamatkis et al., 2016). This highlights polysynaptic pathways through which the SCN could indirectly regulate the LHb.

Alongside PK2 and AVP, LHb neurones are responsive to orexin (Flanigan et al., 2020; Wang et al., 2021). Orexin is a major output molecule of the LH (Aston-Jones et al., 2009; Richardson and Aston-Jones, 2012; Ferrari et al., 2018), and orexinergic neurones undergo circadian regulation from the SCN (Deboer et al., 2004; Marston et al., 2008; Kalsbeek et al., 2011). It is therefore possible that $\mathrm{LHb}$ dependent behaviours, driven by orexin, are under circadian control and that orexin is another mechanism by which daily variations in the $\mathrm{LHb}$ are extrinsically regulated. This is particularly relevant when considering the role of LH orexinergic neurones in driving appetitive drug seeking, a behaviour associated with reward dysfunction typical of aberrant LHb activity (James et al., 2019; Yeoh et al., 2019). 
To complement this evidence for extrinsic circadian regulation of $\mathrm{LHb}$ activity, presynaptic release probability of LHb afferents varies throughout the day (Park et al., 2017). This peaks during late afternoon, coincident with increasing neuronal activity in the LHb (Zhao and Rusak, 2005; Sakhi et al., 2014b). This suggests that circadian variation in LHb activity is driven by an interaction between intrinsic and extrinsic regulation.

In addition to entrainment from the SCN and other secondary oscillators, evidence suggests that LHb activity could be influenced by light. An early tracing study evidenced a direct retinal projection to the LHb (Qu et al., 1996), suggesting that this structure could integrate photic information. Indeed, in vivo electrophysiological recordings show that $\mathrm{LHb}$ neurones respond to light (Zhao and Rusak, 2005; Sakhi et al., 2014b; Huang et al., 2019). However, later tract-tracing indicates that the retina innervates areas just external to the anatomical borders of the LHb (Sakhi et al., 2014b). Further, melanopsin expressing retinal ganglion cells (mRGCs), responsible for light entrainment of the SCN and other oscillators, do not directly target the LHb and instead innervate the adjacent perihabenula (PHb; Hattar et al., 2006; Morin and Studholme, 2014). Moreover, the delay in LHb response to retinal illumination is too slow to reflect a direct retina-LHb connection (Sakhi et al., 2014b), instead indicating that light information is conveyed to the LHb via polysynaptic connections.

Candidates for intermediate structures in this pathway include the ventral lateral geniculate and intergeniculate leaflet (vLGNIGN; Huang et al., 2019). Viral tracing shows that these structures receive direct input from mRGCs, and optogenetic interrogation reveals that activation of this pathway drives inhibitory postsynaptic currents in LHb neurones. Moreover, in vivo electrophysiology reveals that retinal illumination decreases the action potential frequency, and burst frequency, of $\mathrm{LHb}$ neurones in an intensity dependent manner. Another investigation found varying levels of light intensities to increase mouse LHb neuronal activity (Sakhi et al., 2014b). These data highlight the uncertainty surrounding the predominant effect of light in regulating $\mathrm{LHb}$ activity. Light's role in entraining the $\mathrm{LHb}$ to daily rhythms has yet to receive extensive investigation.

Finally, it is worth considering a role for social cues in the regulation of this daily activity. The LHb is implicated in reward processing, and it is embedded within many pathways which regulate reward-based feeding (Stamatkis et al., 2016), drug seeking (Nair et al., 2021), and social behaviour (Valentinova et al., 2019; Rigney et al., 2020). It is possible that the LHb may receive feedback from the drivers of these behaviourswhich accordingly entrain neural activity. Moreover, peak LHb neural activity in vivo is coincident with heightened physical activity levels during a rodent's subjective night (Paul et al., 2011), raising the possibility of a feedback loop entraining the LHb to physical exercise. Behavioural and SCN entrainment to such arousal and other non-photic cues is widely documented (Rosenwasser et al., 1984; Gillman et al., 2013; Crosby et al., 2019; Hughes et al., 2021; Robbers et al., 2021). As the LHb plays such a vital role in integrating this information and coordinating an animal's reward response (Lammel et al., 2012), it is possible that it also responds to variation in this information throughout the day. Interestingly, rhythmic expression of clock genes in the LHb can be dampened by voluntary consumption of a high-fat high-sugar diet, illustrating how food intake may regulate circadian rhythms in this structure (Blancas-Velazquez et al., 2017). However, contrasting research suggests that while this effect occurs throughout the brain, it is absent in the LHb (Blancas-Velazquez et al., 2018). Clearly, more research is required to resolve how hedonic eating, and other social cues, affect daily variation of molecular activity and function in the LHb.

\section{IMPLICATIONS FOR PSYCHIATRIC ILLNESS}

As previously discussed, the LHb is implicated in the pathophysiology of multiple psychiatric illnesses ( $\mathrm{Hu}$ et al., 2020). Numerous depressive phenotypes, in various animal models, are associated with increased LHb activity. For example, elevated $\mathrm{LHb}$ spike frequency is correlated with depressive behaviour for mice in the tail suspension and sucrose preference test, following chronic mild stress (Cerniauskas et al., 2019). Conversely, increasing $\mathrm{GABA}_{\mathrm{B} 1}$ receptor function suppresses $\mathrm{LHb}$ hyperactivity and ameliorates depressive phenotypes (Lecca et al., 2016). This illustrates how bidirectional modulation of LHb activity can drive a two-way regulation of depressive behaviours.

This is likely due to the inverse correlation between LHb activity and the activity of its midbrain targets. The VTA receives direct innervation from the $\mathrm{LHb}$ and activation of this pathway promotes behavioural despair and place avoidance (Cerniauskas et al., 2019). Similarly, there is reciprocal connectivity between the LHb and the raphe nuclei (Sego et al., 2014); with stimulation of the LHb attenuating activity in the raphe (Stern et al., 1979). Paradoxically, though, almost all projections from the LHb are glutamatergic (Aizawa et al., 2012). Excitatory glutamatergic transmission to VTA and raphe neurones, predominantly dopaminergic and serotonergic, respectively, would be predicted to promote antidepressant-like effects. To reconcile this, the role of the RMTg must be considered (Barrot and Thome, 2011; Jhou, 2021).

The RMTg, also called the tail of the VTA, is a predominantly GABAergic midbrain centre which exerts feedforward inhibition onto various monoaminergic structures including the VTA, MR, and DR (Metzger et al., 2021). The LhB innervates the RMTg (Li et al., 2019), and c-Fos-ir in this structure is elevated following LHb stimulation (Lammel et al., 2012). Correspondingly, activation of the RMTg induces pro-depressive behavioural consequences (Stamatakis and Stuber, 2012; Smith et al., 2019), and reduces activity levels in the VTA and raphe nuclei.

The activity of the LHb, and thus feedforward inhibition of midbrain monoaminergic centres, is tightly regulated. Firstly, the VTA is reciprocally connected to the LHb, innervating the 
LHb with gabazine sensitive inhibitory synapses (Stamatakis et al., 2013). Activation of this pathway disinhibits the VTA via the suppression of the LHb, and thus the RMTg. This is one mechanism whereby a LHb-VTA circuit may mediate reward prediction error (Stopper et al., 2014). Elevated LHb activity is correlated with reward omission (Matsumoto and Hikosaka, 2007), and pathological LHb hyperactivity can therefore encode anhedonia typical of depression sufferers (Yang et al., 2018a).

The $\mathrm{LHb}$ also receives extensive innervation from the GPi (or rodent EP; Shabel et al., 2012). This glutamatergic projection promotes aversion learning, and optogenetic stimulation of the EP-LHb pathway conditions avoidance in the place preference test. Activity in this pathway is bidirectionally regulated by expected reward outcome, increasing and decreasing upon worse and better outcomes, respectively (Stephenson-Jones et al., 2016). Intriguingly, GABA and Glutamate can be co-released at the EP-LHb synapse, implicating release balance of these neurotransmitters in encoding mood and reward valence (Shabel et al., 2014).

Similar to the VTA, there is reciprocal connectivity between the LHb and the raphe nuclei (Metzger et al., 2021). Interestingly, despite the well-established role for serotonin signalling in the mechanism of traditional antidepressant drugs (Blier and Montigny, 1998), activation of $5-\mathrm{HT}_{2 \mathrm{C}}$ receptors in the $\mathrm{LHb}$ causes depolarisation and increased spike frequency (Zuo et al., 2016). This is accompanied by the expression of an anhedonic and passive coping phenotype (Han et al., 2015). However, serotonin also decreases release probability of glutamate at the EP-LHb synapse, decreasing EPSP amplitude and potentially reducing excitatory input to the LHb (Shabel et al., 2012). By attenuating excitatory drive to the LHb, hyperactivity is suppressed, thus elucidating a potential mechanism whereby serotonin exerts its antidepressant effects.

There is accumulating evidence that increased LHb burst firing plays a role in the aetiology of depression (Cui et al., 2018; Yang et al., 2018a). For example, the proportion of bursting $\mathrm{LHb}$ neurones is elevated in congenitally learned helpless mice, compared to control animals. Indeed, optogenetic induction of $\mathrm{LHb}$ rebound bursting is sufficient to induce depressivelike behavioural performance in the sucrose preference and tail suspension tests (Yang et al., 2018a). This is demonstrative of a potentially causal relationship between this discharge pattern and depression.

This increase in LHb bursting is possibly associated with enhanced astrocytic expression of the inwardly rectifying potassium channel, Kir4.1 (Cui et al., 2018). Historically, glial expression of Kir4.1 has been colocalised with tripartite synapses (Newman, 1993), where its $\mathrm{K}^{+}$buffering properties controls neuronal membrane potential according to the Nernst equation (Amédée et al., 1998; Neusch et al., 2006; Cui et al., 2018). Dysfunction of Kir4.1 results in local hyperactive neuronal states associated with various pathologies such as Parkinson's and epilepsy (Haj-Yasein et al., 2011; Tong et al., 2014; Nwaobi et al., 2016).

In the LHb, these channels sit within the membrane of astrocytic processes that surround neuronal somata. In this

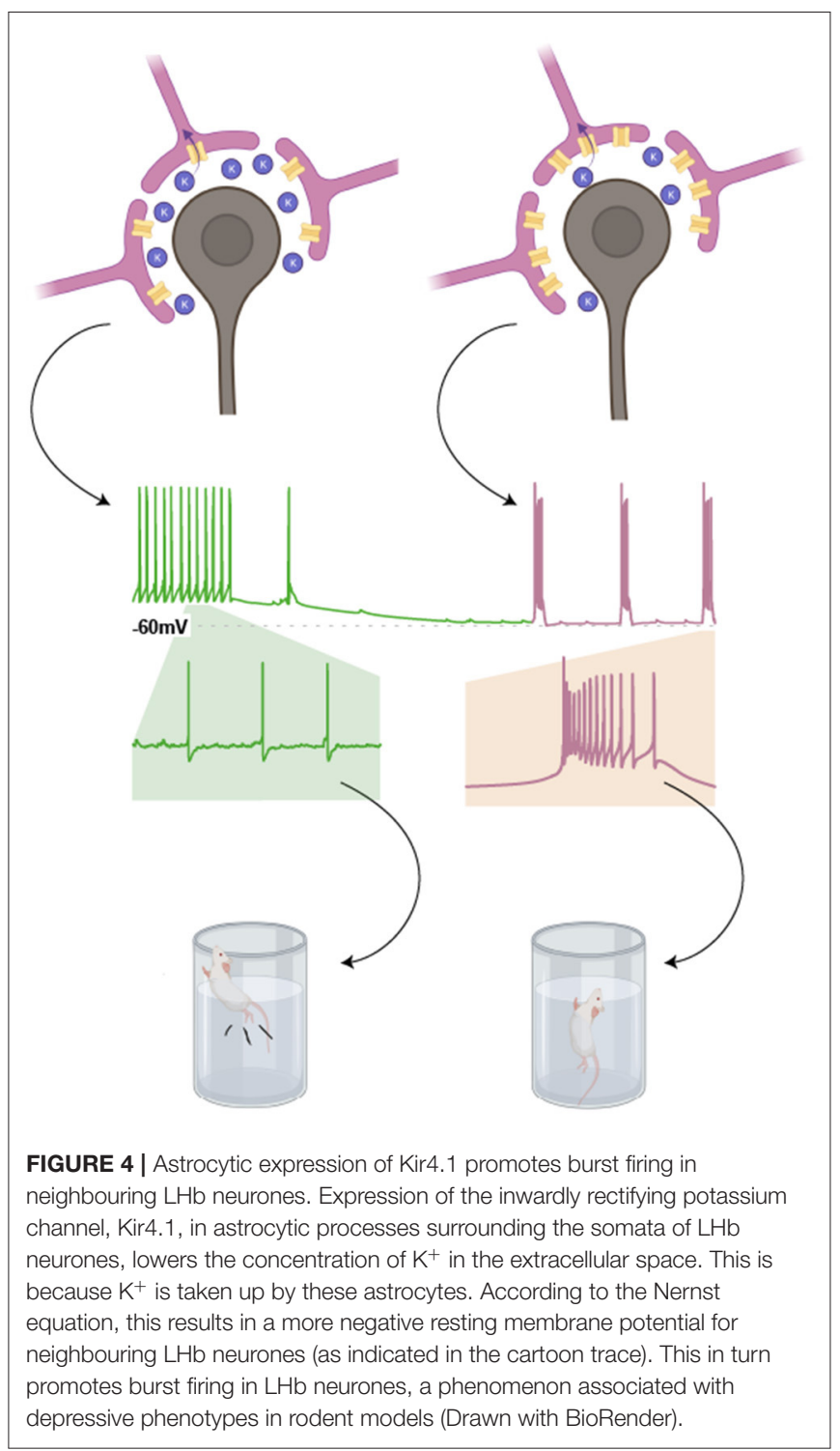

context, Kir 4.1 drives the hyperpolarisation of neighbouring neurones by decreasing the extracellular concentration of $\mathrm{K}^{+}$(Tong et al., 2014). LHb neurones require membrane hyperpolarisation to exhibit burst firing. As such, astrocytic overexpression of Kir4.1 promotes LHb burst firing, and consequent depressive phenotypes (Figure 4).

This link between depression and the voltage dependence of burst firing may explain the paradoxical nature of serotonin's depolarising effects in the lateral habenula (Zuo et al., 2016), and its well-characterised involvement in antidepressant pharmacotherapies (Blier and Montigny, 1998). By causing depolarisation in the $\mathrm{LHb}$, serotonin may shift membrane potential out of a range in which burst firing occurs. In a similar fashion, knockdown of Kir4.1 causes depolarisation in LHb neurones (Cui et al., 2018). This is accompanied by attenuation of burst firing and alleviation of passive 
coping and anhedonic phenotypes in chronically learned helpless mice.

\section{LINKING CIRCADIAN VARIABILITY WITH DEPRESSION, VIA THE LATERAL HABENULA}

Circadian disruptions are common in bipolar disorder and animal models of bipolar disorder (Wulff et al., 2010; Timothy et al., 2018) as well as in people suffering from depression (Jagannath et al., 2013; Mendoza, 2019). Many sufferers struggle to initiate or maintain sleep, and experience aberrant hormonal daily rhythms (e.g., cortisol; Difrancesco et al., 2019; Hoyos et al., 2020). Unpicking the cause-and-effect relationship of this comorbidity is complex, but the circadian and pro-depressive properties of the LHb make it a possible candidate to mediate this interaction.

Circadian variations in LHb activity are a good place to start when considering this interaction. LHb activity levels are closely linked to depression, therefore it would be predicted that peak exhibition of depressive symptoms to be coincident with elevated $\mathrm{LHb}$ firing rate. Mood does show diurnal variation, with negative affect showing more pronounced circadian rhythms in depression sufferers than healthy individuals (Wirz-Justice, 2008). Interestingly, the patterns of mood oscillations are different in healthy individuals compared to those exhibiting depressive mood (Rusting and Larsen, 1998). Low mood sufferers tend to experience an evening-worse pattern of mood, in which low mood is exacerbated in late day. However, some research indicates that, in diagnosed depressives, this peak in low mood occurs in early morning (Zerssen et al., 1985). This is coincident with the lowest behavioural activity in depressed adults over age 30 (Smagula et al., 2021). It is pertinent to note, though, that most recordings which illustrate circadian oscillations in the LHb were made in or from tissue prepared from nocturnal rodents. To fully appreciate how changes in LHb firing rate associate with daily variation in human mood, studies investigating neural activity variations in the LHb of diurnal rodents or indeed humans are necessary.

While circadian variation in spike rate has been independently investigated, it is unknown if the occurrence of burst firing or intraburst frequency alters with time of day/circadian cycles. This could have implications for symptoms of depression, as passive coping and anhedonia are shown to positively correlate with both of these variables (Yang et al., 2018a; Cerniauskas et al., 2019). Although circadian variation in the proportion of bursting LHb cells is not reported, Kir4.1 shows similar oscillatory expression to the clock gene Bmal1 in retinal Müller cells (Luo et al., 2019). As astrocytic Kir4.1 expression is implicated in LHb bursting (Figure 3; Cui et al., 2018), it is possible that circadian oscillations in Kir4.1 drive a corresponding rhythm in burst firing and resultant depressive behaviours. Moreover, Kir4.1 expression is additionally regulated by insulin receptor substrate1 (IRS-1; Luo et al., 2019), with increased IRS-1 signalling causing an upregulation of Kir4.1. Interestingly, the habenula complex is an enriched site for IRS-1 (Baskin et al., 1993). This suggests a potential mechanism whereby LHb activity is entrained by diet, with post-feeding surges in insulin causing increased IRS-1 signalling and thus changes in Kir4.1 expression (Crosby et al., 2019). Such a process could also explain how high-sugar diets may exacerbate depression (Vermeulen et al., 2017).

Circadian oscillations in LHb activity may entrain $24 \mathrm{~h}$ oscillations in the activity and function of neural structures that are targeted by LHb efferents (Mendoza, 2017). Some VTA neurones exhibit circadian variation in electrophysiological properties (Luo et al., 2008), and disruptions in these normal oscillations are associated with mood switching, typical of bipolar disorder (Sidor et al., 2016). The VTA shows circadian oscillations in clock gene expression (Webb et al., 2009), and is directly innervated by the SCN (Luo and AstonJones, 2009), both of which may entrain VTA function to its daily rhythms. However, LHb-VTA connectivity is another mechanism through which circadian variation in the VTA may occur. This particular pathway may be responsible for circadian oscillations in motivation and reward valency (Webb et al., 2009; Acosta et al., 2020). Aberrations in this process could explain the dysregulated reward seeking behaviour typical of addiction, or the anhedonia described in depression sufferers (Fox and Lobo, 2019). This is reinforced by the observation that arrhythmic animals show an overall decrease in motivation (Acosta et al., 2020).

Similar to the VTA, serotonergic raphe neurones appear to be under circadian control from the LHb (Mendoza, 2017). Serotonin release, throughout the brain, is heightened during the active night of nocturnal rodents (Dudley et al., 1998). There are some direct glutamatergic projections from the $\mathrm{LHb}$ to the DR, and electrical stimulation of these increase serotonin release (Kalen et al., 1989). Further, in vivo recordings of $\mathrm{LHb}$ neurones projecting to the DR show an elevated spike rate at night (Liu et al., 2021). This may explain the coincident peaks in LHb neural activity and serotonin release.

This circadian variation was blunted in stress susceptible mice, with an overall increase in activity at both day and night (Liu et al., 2021). Such stress susceptibility may be encoded by reciprocal serotonergic projections from the DR to the $\mathrm{LHb}$, which thus increase LHb spike rate (Zuo et al., 2016). Alternatively, these recordings may have been taken from inhibitory pathways which inhibit serotonergic activity. To resolve these possibilities, recordings in postsynaptic raphe neurones are required.

Entrainment of LHb activity, by light, potentially underpins resistance to depressive mood. Bright light therapy (BLT) is an effective chronotherapy when administered in the early morning (Olejniczak et al., 2021), and is especially effective at treating seasonal affective disorder (Pjerk et al., 2020). In the forced swim test, passive coping behaviour is attenuated by transient light pulses during late night (Olejniczak et al., 2021). This suggests that light itself does not provide the antidepressant effect, but instead causes a circadian phase 
shift (Menculini et al., 2018). A putative pathway, connecting the retina to the vLGN-IGN and onward to the LHb, is thought to mediate the anti-depressive effect of BLT (Huang et al., 2019). Optogenetic activation of this pathway elicits an antidepressant effect in the sucrose preference and forced swim test, and these effects are replicated following retinal illumination. However, light suppresses active behaviour raising the possibility that observed changes are the consequence of a non-circadian "masking" effect (Redlin, 2001). Moreover, projections from the retina to the $\mathrm{PHb}$ are associated with mood regulation (Fernandez et al., 2018). Mice exposed to aberrant light conditions exhibit anhedonic and passive coping behaviours, and this is thought to be mediated via $\mathrm{PHb}$ neurones. This is another example of non-circadian response to light, near the habenula complex, which could explains light's regulation of affect.

An alternative explanation for the antidepressant-like effects of BLT is its capacity to induce Per1 expression. This occurs in the SCN, and the LHb (Yan and Silver, 2002; Kuhlman et al., 2003; Olejniczak et al., 2021). More importantly, the capacity for BLT to elicit antidepressant-like effects appears to depend on Per1 expression in the LHb and is abrogated by Per 1 knockdown in this structure. However, this may not be demonstrative of a causal relationship between Per1 induction and antidepressantlike effects of BLT. Per1 controls the transcription of various ion channels (Gumz et al., 2010; Stow et al., 2012; Alli et al., 2019) which regulate neuronal excitability (Carr et al., 2001; Lang et al., 2003; Amin et al., 2005). Upon Per1 knockdown, these proteins become unregulated and the $\mathrm{LHb}$ could default to a state of hyperactivity. Interestingly, in the Cry $1^{-/-} \mathrm{Cr} y 2^{-/-}$mouse in which the molecular clock does not function, LHb spiking activity is around an intermediate level (Sakhi et al., 2014b), indicating that more investigation is necessary to determine if and how altered clock gene expression influences neuronal excitability.

Other studies support the contention that the molecular clock is involved in depression. For example, Per2 knockdown in the $\mathrm{LHb}$ results in a passive coping phenotype during night-time ( $\mathrm{Li}$ et al., 2020). Moreover, the antidepressant effects of ketamine have been associated with its impact on the molecular clock. Ketamine administration can dampen clock gene oscillations by interfering with the CLOCK:Bmall heterodimer (Bellet et al., 2011), which occurs in a GSK3 $\beta$ dependent manner. Ketamine's antidepressant effects are also dependent on GSK3 $\beta$ (Zanos and Gould, 2018), thus linking the molecular clock to depression. However, no behaviour experiments have yet shown a correlation between ketamine's effect on CLOCK:Bmall and depressive phenotypes.

If the exact nature of clock gene function in depression is questionable, their relevance in the entrainment of circadian oscillators is not. However, other cues are also important and may contribute to the link between circadian disruptions and depression. One example of this may be stress. Exposure to stressful stimuli can profoundly interrupt normal reward processing, a behavioural effect triggered by synaptic depression in the LHb (Nuno-Perez et al., 2021). Alongside this, acute stress is able to transform $\mathrm{LHb}$ reward responses into punishment-like signals, and this occurs synchronously with onset of anhedonic behaviour (Shabel et al., 2019). These stress signals can also cause circadian disruptions (Kalmbach et al., 2018). In fact, there has been an unprecedented rise in sleep disturbances as a consequence of the COVID-19 pandemic (Morin et al., 2020), an event which is concomitant with elevated depression and anxiety levels (Luo et al., 2020). The susceptibility of the LHb to stress, and its role as a neural circadian oscillator, places it well to mediate this link between stress dependent circadian disruptions and affective disorders.

In addition to stress, arousal-promoting stimuli such as physical exercise entrain circadian rhythms (Mistlberger and Antle, 2011; Hughes and Piggins, 2012). Scheduled exercise can entrain the SCN and behavioural rhythms in animals with otherwise disrupted activity patterns (Power et al., 2010; Hughes et al., 2021). There is also evidence of a feedback loop coordinating LHb activity with exercise (Paul et al., 2011), and animals with LHb Per1 knockdown exhibit blunted behavioural rhythms (Li et al., 2020). Lower levels of exercise are associated with depression (Mcmahon et al., 2017), and exercise-based interventions can alleviate symptoms in sufferers (Cramer et al., 2013; Paolucci et al., 2018; Schuch and Stubbs, 2019). It is possible that there is a circadian association between depression and exercise, and that timed exercise intervention may benefit depression sufferers by entraining their otherwise disrupted diurnal rhythms (Hughes et al., 2021). If this this proves to be the case, the LHb may be a critical component in the neural circuitry which underpins it.

\section{CONCLUSION}

The LHb varies its activity over $24 \mathrm{~h}$, and this epithalamic area is ideally situated to mediate the links between depression and circadian disruption. It is a highly heterogeneous structure that resides within an anatomically diffuse neural circadian network, potentially receiving circadian entrainment signals from other neural oscillators, arousal, and social cues, as well as light input. The LHb's role in the regulation of reward processing, and the function this has in entraining rhythms according to motivation, evidences a connections between these rhythms and mood. Aberrant and dysregulated reward seeking is characteristic of various psychiatric disorders, and disruptions in LHb signalling may underpin this.

Extensive further research is necessary before firm conclusions can be drawn regarding the importance of changes in the circadian function of the LHb in the aetiology of depression. To date, most of the evidence supporting this conjecture is of a correlational or associative nature and here we have highlighted potential avenues for future investigation. Indeed, preliminary work is emerging which focusses on the role of circadian oscillations in LHb-dependent depression and antidepressant treatments. While important to understanding depression, such approaches need to be carefully critiqued to fully elucidate the complexity of the LHb's role in both depression and circadian timekeeping in general. 


\section{DATA AVAILABILITY STATEMENT}

The original contributions presented in the study are included in the article/supplementary material, further inquiries can be directed to the corresponding author.

\section{AUTHOR CONTRIBUTIONS}

CY and HP wrote and edited the manuscript. DL edited the manuscript. CY and DL composed the figures. All authors contributed to the article and approved the submitted version.

\section{REFERENCES}

Acosta, J., Bussi, I. L., Esquivel, M., Hocht, C., Golombek, D. A., and Agostino, P. V. (2020). Circadian modulation of motivation in mice. Behav. Brain Res. 382:112471. doi: 10.1016/j.bbr.2020.112471

Aizawa, H., Amo, R., and Okamoto, H. (2011). Phylogeny and ontogeny of the habenular structure. Front. Neurosci. 5:138. doi: 10.3389/fnins.2011.00138

Aizawa, H., Kobayashi, M., Tanaka, S., Fukai, T., and Okamoto, H. (2012). Molecular characterization of the subnuclei in rat habenula. J. Comp. Neurol. 520, 4051-4066. doi: 10.1002/cne.23167

Alli, A., Yu, L., Holzworth, M., Richards, J., Cheng, K.-Y., Lynch, I. J., et al. (2019). Direct and indirect inhibition of the circadian clock protein Per1: effects on ENaC and blood pressure. Am. J. Physiol. Renal Physiol. 316, F807-F813. doi: 10.1152/ajprenal.00408.2018

Amédée, T., Robert, A., and Coles, J. A. (1998). Potassium homeostasis and glial energy metabolism. Glia 21, 46-55. doi: 10.1002/(SICI)10981136(199709)21:1<46::AID-GLIA5>3.0.CO;2-\#

Amin, M. S., Wang, H.-W., Reza, E., Whitman, S. C., Tuana, B. S., and Lenen, F. H. H. (2005). Distribution of epithelial sodium channels and mineralocorticoid receptors in cardiovascular regulatory centers in rat brain. Am. J. Physiol. Regul. Integr. Comp. Physiol. 289, R1787-R1797. doi: 10.1152/ajpregu.00063.2005

Aston-Jones, G., Smith, R. J., Moorman, D. E., and Richardson, K. A. (2009). Role of lateral hypothalamic orexin neurons in reward processing and addiction. Neuropharmacology 56, 112-121. doi: 10.1016/j.neuropharm.2008.06.060

Bano-Otalora, B., and Piggins, H. D. (2017). Contributions of the lateral habenula to circadian timekeeping. Pharmacol. Biochem. Behav. 162, 46-54. doi: $10.1016 /$ j.pbb.2017.06.007

Barrot, M., and Thome, J. (2011). Discovering a new anatomical structure in the brain: implications for neuropsychiatry and therapy. World J. Biol. Psychiatry 12, 19-22. doi: 10.3109/15622975.2011.598386

Baskin, D. G., Sipols, A. J., Schwartz, M. W., and White, M. F. (1993). Immunocytochemical detection of insulin receptor substrate-1 (IRS-1) in rat brain: colocalization with phosphotyrosine. Regul. Peptides 48, 257-266. doi: 10.1016/0167-0115(93)90355-C

Bellet, M. M., Vawter, M. P., Bunney, B. G., Bunney, W. E., and SassoneCorsi, P. (2011). Ketamine influences CLOCK:BMAL1 function leading to altered circadian gene expression. PLoS ONE 6:e23982. doi: 10.1371/journal.pone.0023982

Bianco, I. H., and Wilson, S. W. (2009). The habenular nuclei: a conserved asymmetric relay station in the vertebrate brain. Philos. Trans. R. Soc. B 364, 1005-1020. doi: 10.1098/rstb.2008.0213

Blancas-Velazquez, A., La Fleur, S. E., and Mendoza, J. (2017). Effects of a freechoice high-fat high-sugar diet on brain PER2 and BMAL1 protein expression in mice. Appetite 117, 263-269. doi: 10.1016/j.appet.2017.07.002

Blancas-Velazquez, A. S., Unmehopa, U. A., Eggels, L., Koekkoek, L., Kalsbeek, A., Mendoza, J., et al. (2018). A free-choice high-fat high-sugar diet alters day-night Per2 gene expression in reward-related brain areas in rats. Front. Endocrinol. 9:154. doi: 10.3389/fendo.2018.00154

Blier, P., and Montigny, C. D. (1998). Possible serotonergic mechanisms underlying antidepressant and anti-obsessive-compulsive disorder responses. Biol. Psychiatry 44, 313-323. doi: 10.1016/S0006-3223(98)00114-0

\section{FUNDING}

CY was supported by a studentship from the Biotechnology and Biological Sciences Research Council (BBSRC; UK) South West Biosciences Doctoral Training Programme (BB/T008741/1). Research in HP's lab was supported by project grants from the BBSRC (BB/R019223 and BB/W000865).

\section{ACKNOWLEDGMENTS}

We thank Eleanor Bell and Dr. Adriana Basnakova for stimulating discussions.

Buijs, R. M. (1978). Intra - and extrahypothalamic vasopressin and oxytocin pathways in the rat. Cell Tissue Res. 192, 423-435. doi: 10.1007/BF00224932

Cagampang, F. R. A., Yang, J., Nakayama, Y., Fukuhara, C., and Inouye, S.-I. T. (1994). Circadian variation of arginine-vasopressin messenger RNA in the rat suprachiasmatic nucleus. Mol. Brain Res. 24, 179-184. doi: 10.1016/0169-328X(94)90130-9

Carr, M. J., Gover, T. D., Weinreich, D., and Undem, B. J. (2001). Inhibition of mechanical activation of guinea-pig airway afferent neurons by amiloride analogues. Br. J. Pharmacol. 133, 1255-1262. doi: 10.1038/sj.bjp.0704197

Cerniauskas, I., Winterer, J., De Jong, J. W., Lukacsovich, D., Yang, H., Khan, F., et al. (2019). Chronic stress induces activity, synaptic, and transcriptional remodeling of the lateral habenula associated with deficits in motivated behaviors. Neuron 104, 899-915. doi: 10.1016/j.neuron.2019.09.005

Charlson, F., Ommeren, M. V., Flaxman, A., Cornett, J., and Whiteford, H. And Saxena, S. (2019). New WHO prevalence estimates of mental disorders in conflict settings: a systematic review and meta-analysis. Lancet 394, 240-248. doi: 10.1016/S0140-6736(19)30934-1

Christiansen, S. L., Bouzinova, E. V., Fahrenkrug, J., and Wiborg, O. (2016). Altered expression pattern of clock genes in a rat model of depression. Int. J. Neuropsychopharmacol. 19:61. doi: 10.1093/ijnp/pyw061

Corriger, A., and Pickering, G. (2019). KEtamine and depression: a narrative review. Drug Design Dev. Ther. 13, 3051-3067. doi: 10.2147/DDDT.S221437

Cramer, H., Lauche, R., Langhorst, J., and Dobos, G. (2013). Yoga for depression: a systematic review and meta-analysis. Depr. Anxiety 30, 1068-1083. doi: $10.1002 /$ da.22166

Crosby, P., Hamnett, R., Putker, M., Hoyle, N. P., Reed, M., Karam, C. J., et al. (2019). Insulin/IGF-1 drives PERIOD synthesis to entrain circadian rhythms with feeding time. Cell 177, 896-909. doi: 10.1016/j.cell.2019.02.017

Cui, Y., Yang, Y., Ni, Z., Dong, Y., Cai, G., Foncelle, A., et al. (2018). Astroglial Kir4.1 in the lateral habenula drives neuronal bursts in depression. Nature 14, 323-327. doi: 10.1038/nature25752

Deboer, T., Overseem, S., Visser, N. A. H., Duindam, H., Frolich, M., Lammers, G. J., et al. (2004). Convergence of circadian and sleep regulatory mechanisms on hypocretin-1. Neuroscience 129, 727-732. doi: 10.1016/j.neuroscience.2004.07.049

Diaz, E., Bravo, D., Rojas, X., and Concha, M. L. (2011). Morphologic and immunohistochemical organization of the human habenular complex. J. Comp. Neurol. 519, 3727-3747. doi: 10.1002/cne.22687

Difrancesco, S., Lemers, F., Riese, H., Merikangas, K. R., Beekman, A. T. F., Van Hemert, A. M., et al. (2019). Sleep, circadian rhythm, and physical activity patterns in depressive and anxiety disorders: A 2-week ambulatory assessment study. Depres. Anxiety 36, 975-986. doi: 10.1002/da.22949

Dudley, T. E., Dinardo, L. A., and Glass, J. D. (1998). Endogenous regulation of serotonin release in the hamster suprachiasmatic nucleus. J. Neurosci. 18, 5045-5052. doi: 10.1523/JNEUROSCI.18-13-05045.1998

Fernandez, D. C., Fogerson, P. M., Ospri, L. L., Thomsen, M. B., Layned, R. M., Severin, D., et al. (2018). Light affects mood and learning through distinct retina-brain pathways. Cell 175, 71-84 doi: 10.1016/j.cell.2018.08.004

Ferrari, L. L., Park, D., Zhu, L., Palmer, M. R., Broadhurst, R. Y., and Arrigoni, E. (2018). Regulation of lateral hypothalamic orexin activity by local GABAergic neurons. J. Neurosci. 36, 1588-1599. doi: 10.1523/JNEUROSCI.1925-17.2017 
Flanigan, M. E., Aleyasin, H., Li, L., Burnett, C. J., Chan, K. L., Leclair, K. B., et al. (2020). Orexin signaling in GABAergic lateral habenula neurons modulates aggressive behavior in male mice. Nat. Neurosci. 23, 638-650. doi: 10.1038/s41593-020-0617-7

Fowler, C. D., Lu, Q., Johnson, P. M., Marks, M. J., and Kenny, P. J. (2011). Habenular $\alpha 5$ nicotinic receptor subunit signalling controls nicotine intake. Nature 471, 597-601. doi: 10.1038/nature09797

Fox, M. E., and Lobo, M. K. (2019). The molecular and cellular mechanisms of depression: a focus on reward circuitry. Mol. Psychiatry 24, 1798-1815. doi: $10.1038 /$ s41380-019-0415-3

GBD 2017 Disease and Injury Incidence and Prevalence Collaborators. (2018). Global, regional, and national incidence, prevalence, and years lived with disability for 354 diseases and injuries for 195 countries and territories, 1990-2017: a systematic analysis for the Global Burden of Disease Study 2017. Lancet 392, 1789-1858. doi: 10.1016/S0140-6736(18)32279-7

Gillman, A. G., Leffel, J. K., Kosobud, A. E. K., and Timberlake, W. (2013). Behavioral characteristics and pharmacological manipulations of a nicotine-entrainable circadian oscillator. Chronobiol. Int. 30, 855-869. doi: 10.3109/07420528.2013.782314

Glick, S. D., Ramirez, R. L., Livi, J. M., and Maisonneuve, I. M. (2006). 18Methoxycoronaridine acts in the medial habenula and/or interpeduncular nucleus to decrease morphine self-administration in rats. Euro. J. Pharmacol. 537, 94-98. doi: 10.1016/j.ejphar.2006.03.045

Guilding, C., Hughes, A. T., Brown, T. M., Namvar, S., and Piggins, H. D. (2009). A riot of rhythms: neuronal and glial circadian oscillators in the mediobasal hypothalamus. Mol. Brain 2:28. doi: 10.1186/1756-6606-2-28

Guilding, C., Hughes, A. T. L., and Piggins, H. D. (2010). Circadian oscillators in the epithalamus. Neuroscience 169, 1630-1639. doi: 10.1016/j.neuroscience.2010.06.015

Guilding, C., and Piggins, H. D. (2007). Challenging the omnipotence of the suprachiasmatic timekeeper: are circadian oscillators present throughout the mammalian brain? Euro. J. Neurosci. 25, 3195-3216. doi: 10.1111/j.1460-9568.2007.05581.x

Guilding, C., Scott, F., Bechtold, D. A., Brown, T. M., Wegner, S., and Piggins, H. D. (2013). Suppressed cellular oscillations in after-hours mutant mice are associated with enhanced circadian phase-resetting. J. Physiol. 591, 1063-1080. doi: 10.1113/jphysiol.2012.242198

Gumz, M. L., Cheng, K.-Y., Lynch, I. J., Stow, L. R., Greenlee, M. M., Cain, B. D., et al. (2010). Regulation of $\alpha \mathrm{ENaC}$ expression by the circadian clock protein Period 1 in mpkCCD(c14) cells. Biochim. Biophys. Acta 1799, 622-629. doi: 10.1016/j.bbagrm.2010.09.003

Haj-Yasein, N. N., Jensen, V., Vindedal, G. F., Gundersen, G. A., Klungland, A., Ottersen, O. P., et al. (2011). Evidence that compromised K+ spatial buffering contributes to the epileptogenic effect of mutations in the human kir4.1 gene (KCNJ10). Glia 59, 1635-1642. doi: 10.1002/glia.21205

Han, L.-N., Zhang, L., Li, L.-B., Sun, Y.-N., Wang, Y., Chen, L., et al. (2015). Activation of $5-\mathrm{Ht} 2 \mathrm{c}$ receptors in the $\mathrm{LHb}$ nucleus increases the expression of depression-related behaviours in the hemiparkinsonian rat. Neuropharmacology 93, 68-79. doi: 10.1016/j.neuropharm.2015.01.024

Hashikawa, Y., Hashikawa, K., Rosi, M. A., Basiri, M. L., Liu, Y., Johnstor, N. L., et al. (2020). Transcriptional and spatial resolution of cell types in the mammalian habenula. Neuron 106, 743-758. doi: 10.1016/j.neuron.2020.03.011

Hastings, M. H., Maywood, E. S., and Brancaccio, M. (2018). Generation of circadian rhythms in the suprachiasmatic nucleus. Nat. Rev. Neurosci. 19, 453-469. doi: 10.1038/s41583-018-0026-Z

Hattar, S., Kumar, M., Park, A., Tong, P., Tung, J., Yau, K. W., et al. (2006). Central projections of melanopsin-expressing retinal ganglion cells in the mouse. $J$. Comp. Neurol. 497, 326-340. doi: 10.1002/cne.20970

$\mathrm{He}$, Q., Wang, J., and Hu, H. (2019). Illuminating the activated brain: emerging activity-dependent tools to capture and control functional neural circuits. Neurosci. Bull. 35, 369-377. doi: 10.1007/s12264-018-0291-x

Hergerl, U., Althaus, D., and Stefanek, J. (2003). Public attitudes toward treatment of depression: effects of an information campaign. Pharmacopsychiatry 36, 288-291. doi: 10.1055/s-2003-45115

Herkenham, M., and Nauta, W. J. H. (1977). Afferent Connections of the Habenular Nuclei in the Rat. A Horseradish Peroxidase Study, with a Note on the Fiber-of-Passage Problem. Neuroanatomy. Contemporary Neuroscientists
(Selected Papers of Leaders in Brain Research). Boston, MA: Birkhäuser. doi: 10.1007/978-1-4684-7920-1_16

Herkenham, M., and Nauta, W. J. H. (1979). Efferent connections of the habenular nuclei in the rat. J. Comp. Neurol. 187, 19-47. doi: 10.1002/cne.901870103

Hernandez, V. S., Vazquez-Juarez, E., Marquez, M. M., Jauregui-Huerta, F., Barrio, R. A., and Zhang, L. (2015). Extra-neurohypophyseal axonal projections from individual vasopressin-containing magnocellular neurons in rat hypothalamus. Front. Neuroanat. 9:130. doi: 10.3389/fnana.2015.00130

Hikosaka, O. (2010). The habenula: from stress evasion to value-based decisionmaking. Nat. Rev. Neurosci. 11, 503-513. doi: 10.1038/nrn2866

Horowitz, J. M., and Graf, N. (2019). Most U.S. Teens See Anxiety and Depression as a Major Problem Among their Peers. Washington, DC: Pew Research Center.

Hoyos, C. M., Gordon, C., Terpening, Z., Norrie, L., Lewis, S. J. G., Hickie, I. B., et al. (2020). Circadian rhythm and sleep alterations in older people with lifetime depression: a case-control study. BMC Psychiatry 20:192. doi: 10.1186/s12888-020-02606-Z

Hsu, Y.-W. A., Tempest, L., Quina, L. A., Wei, A. D., Zeng, H., and Turner, E. E. (2013). Medial habenula output circuit mediated by $\alpha 5$ nicotinic receptorexpressing GABAergic neurons in the interpeduncular nucleus. J. Neurosci. 33, 18022-18035. doi: 10.1523/JNEUROSCI.2927-13.2013

Hu, H., Cui, Y., and Yang, Y. (2020). Circuits and functions of the lateral habenula in health and disease. Nat. Rev. Neurosci. 21, 277-295. doi: 10.1038/s41583-020-0292-4

Huang, L., Xi, Y., Peng, Y., Yang, Y., Huang, X., Fu, Y., et al. (2019). A visual circuit related to habenula underlies the antidepressive effects of light therapy. Neuron 102, 128-142. doi: 10.1016/j.neuron.2019.01.037

Hughes, A. T. L., and Piggins, H. D. (2012). "Chapter 18 - feedback actions of locomotor activity to the circadian clock," in The Neurobiology of Circadian Timing, eds A. Kalsbeek, M. Merrow, T. Roenneberg, and R. G. Foster (Amsterdam; Oxford: Elsevier). doi: 10.1016/B978-0-444-59427-3.00018-6

Hughes, A. T. L., Samuels, R. E., Bano-Otalora, B., Belle, M. D. C., Wegner, S., Guilding, C., et al. (2021). Timed daily exercise remodels circadian rhythms in mice. Commun. Biol. 4:761. doi: 10.1038/s42003-021-02239-2

Jagannath, A., Peirson, S. N., and Foster, R. G. (2013). Sleep and circadian rhythm disruption in neuropsychiatric illness. Curr. Opin. Neurobiol. 23, 888-894. doi: 10.1016/j.conb.2013.03.008

James, M. H., Stopper, C. M., Zimmer, B. A., Koll, N. E., Bowrey, H. E., and Aston-Jones, G. (2019). Increased number and activity of a lateral subpopulation of hypothalamic orexin/hypocretin neurons underlies the expression of an addicted state in rats. Biol. Psychiatry 85, 925-935. doi: 10.1016/j.biopsych.2018.07.022

Jhou, T. C. (2021). The rostromedial tegmental (RMTg) "brake" on dopamine and behavior: a decade of progress but also much unfinished work. Neuropharmacology 198:108763. doi: 10.1016/j.neuropharm.2021.108763

Kalen, P., Strecker, R. E., Rosengren, E., and Bjorklund, A. (1989). Regulation of striatal serotonin release by the lateral habenula-dorsal raphe pathway in the rat as demonstrated by in vivo microdialysis: role of excitatory amino acids and GABA. Brain Res. 492, 187-202. doi: 10.1016/0006-8993(89)90901-3

Kalmbach, D. A., Anderson, J. R., and Drake, C. L. (2018). The impact of stress on sleep: pathogenic sleep reactivity as a vulnerability to insomnia and circadian disorders. J. Sleep Res. 27:e12710. doi: 10.1111/jsr.12710

Kalsbeek, A., Scheer, F. A., Perreau-Lenz, S., La Fleur, S. E., Yi, C.-X., Fliers, E., et al. (2011). Circadian disruption and SCN control of energy metabolism. FEBS Lett. 585, 1412-1426. doi: 10.1016/j.febslet.2011.03.021

Kim, U., and Chang, S.-Y. (2005). Dendritic morphology, local circuitry, and intrinsic electrophysiology of neurons in the rat medial and lateral habenular nuclei of the epithalamus. J. Comp. Neurol. 483, 236-250. doi: $10.1002 /$ cne. 20410

Kuhlman, S. J., Silver, R., Le Sauter, J., Bult-Ito, A., and Mcmahon, D. G. (2003). Phase resetting light pulses induce Per1 and persistent spike activity in a subpopulation of biological clock neurons. J. Neurosci. 23, 1441-1450. doi: 10.1523/JNEUROSCI.23-04-01441.2003

Lammel, S., Lim, B. K., Ran, C., Huang, K. W., Betley, M. J., Tye, K. M., et al. (2012). Input-specific control of reward and aversion in the ventral tegmental area. Nature 49, 212-217. doi: 10.1038/nature11527

Lang, F., Henke, G., Embark, H. M., Waldegger, S., Palmada, M., Bohmer, C., et al. (2003). Regulation of channels by the serum and glucocorticoid-inducible 
kinase - implications for transport, excitability and cell proliferation. Cell Physiol. Biochem. 13, 41-50. doi: 10.1159/000070248

Laurent, V., Wong, F. L., and Balleine, B. W. (2017). The lateral habenula and its input to the rostromedial tegmental nucleus mediates outcome-specific conditioned inhibition. J. Neurosci. 37, 10932-10942. doi: 10.1523/JNEUROSCI.3415-16.2017

Lawson, R. P., Nord, C. L., Seymour, B., Thomas, D. L., Dayan, P., Pilling, S., et al. (2017). Disrupted habenula function in major depression. Mol. Psychiatry 22, 202-208. doi: 10.1038/mp.2016.81

Lecca, S., Pelosi, A., Tchenio, A., Moutkine, I., Lujan, R., Herve, D., et al. (2016). Rescue of GABAB and GIRK function in the lateral habenula by protein phosphatase $2 \mathrm{~A}$ inhibition ameliorates depression-like phenotypes in mice. Nat. Med. 22, 254-261. doi: 10.1038/nm.4037

Li, B., Piriz, J., Mirrione, M., Chung, C. H., Proulx, C. D., Shultz, D., et al. (2011). Synaptic potentiation onto habenula neurons in the learned helplessness model of depression. Nature. 470, 535-539. doi: 10.1038/nature09742

Li, H., Pullman, D., and Jhou, T. C. (2019). Valence-encoding in the lateral habenula arises from the entopeduncular region. Elife 8:e41223. doi: 10.7554/eLife.41223

Li, J., Kang, S., Fu, R., Wu, L., Wu, W., Liu, H., et al. (2017). Inhibition of AMPA receptor and CaMKII activity in the lateral habenula reduces depressivelike behavior and alcohol intake in rats. Neuropharmacology 126, 108-120. doi: 10.1016/j.neuropharm.2017.08.035

Li, K., Liao, L., Yang, Z., Wong, C., Henn, F., Malinow, R., et al. (2013). BCaMKII in lateral habenula mediates core symptoms of depression. Science 30, 1016-1020. doi: 10.1126/science.1240729

Li, Y., Li, G., Li, J., Cai, X., Sun, Y., Zhang, B., et al. (2020). Depression-like behavior is associated with lower Per2 mRNA expression in the lateral habenula of rats. Genes Brain Behav. 20:e12702. doi: 10.1111/gbb.12702

Lima, L. B., Bueno, D., Leite, F., Souza, S., Goncalves, L., Furigo, I. C., et al. (2017). Afferent and efferent connections of the interpeduncular nucleus with special reference to circuits involving the habenula and raphe nuclei. J. Comp. Neurol. 525, 2411-2442. doi: 10.1002/cne.24217

Liu, H., Rastogi, A., Narain, P., Xu, Q., Sabanovic, M., Alhammadi, A. D., et al. (2021). Blunted diurnal firing in lateral habenula projections to dorsal raphe nucleus and delayed photoentrainment in stress-susceptible mice. PLoS Biol. 19:e30000709. doi: 10.1371/journal.pbio.3000709

Lopez, A. J., Jia, Y., White, A. O., Kwapis, J. L., Espinoza, M., Hwang, P., et al. (2018). Medial habenula cholinergic signaling regulates cocaine-associated relapse-like behavior. Addict. Biol. 24, 403-413. doi: 10.1111/adb.12605

Luo, A. H., and Aston-Jones, G. (2009). Circuit projections from suprachiasmatic nucleus to ventral tegmental area: a novel circadian output pathway. Euro. J. Neurosci. 29, 748-760. doi: 10.1111/j.1460-9568.2008.06606.x

Luo, A. H., Georges, F. E., and Aston-Jones, G. S. (2008). Novel neurons in ventral tegmental area fire selectively during the active phase of the diurnal cycle. Euro. J. Neurosci. 27, 408-422. doi: 10.1111/j.1460-9568.2007.05985.x

Luo, M., Guo, L., Yu, M., Jiang, W., and Wang, H. (2020). The psychological and mental impact of coronavirus disease 2019 (COVID-19) on medical staff and general public - a systematic review and meta-analysis. Psychiatry Res. 291:113190. doi: 10.1016/j.psychres.2020.113190

Luo, Q., Xiao, Y., Alex, A., Cummins, T. R., and Bhatwadekar, A. D. (2019). Diurnal rhythm of insulin receptor substrate-1 (IRS-1) and Kir4.1 in diabetes: implications for a Clock Gene BMAL1. Retinal Cell Biol. 60, 1928-1936. doi: $10.1167 /$ iovs.18-26045

Marston, O. J., Williams, R. H., Canal, M. M., Samuels, R. E., Upton, N., and Piggins, H. D. (2008). Circadian and dark-pulse activation of orexin/hypocretin neurons. Mol. Brain 1:19. doi: 10.1186/1756-6606-1-19

Matsumoto, M., and Hikosaka, O. (2007). Lateral habenula as a source of negative reward signals in dopamine neurons. Nature 447, 1111-1115. doi: $10.1038 /$ nature 05860

Mcmahon, E. M., Corcoran, P., O’regan, G., Keeley, H., Cannon, M., Carli, V., Wasserman, C., et al. (2017). Physical activity in European adolescents and associations with anxiety, depression and well-being. Euro. Child Adolesc. Psychiatry 26, 111-122. doi: 10.1007/s00787-016-0875-9

Menculini, G., Verdolini, N., Murru, A., Pacchiarotti, I., Volpe, U., Cervino, A., et al. (2018). Depressive mood and circadian rhythms disturbances as outcomes of seasonal affective disorder treatment: a systematic review. J. Affect. Disord. 241, 608-626. doi: 10.1016/j.jad.2018.08.071
Mendoza, J. (2017). Circadian neurons in the lateral habenula: clocking motivated behaviors. Pharmacol. Biochem. Behav. 162, 55-61. doi: 10.1016/j.pbb.2017.06.013

Mendoza, J. (2019). Circadian insights into the biology of depression: symptoms, treatments and animal models. Behav. Brain Res. 376:112186. doi: 10.1016/j.bbr.2019.112186

Metzger, M., Souza, R., Lima, L. B., Bueno, D., Goncalbes, L., Sego, C., et al. (2021). Habenular connections with the dopaminergic and serotonergic system and their role in stress-related psychiatric disorders. Euro. J. Neurosci. 53, 65-88. doi: 10.1111/ejn.14647

Mistlberger, R. E., and Antle, M. C. (2011). Entrainment of circadian clocks in mammals by arousal and food. Essays Biochem. 49, 119-136. doi: $10.1042 /$ bse 0490119

Morin, C. M., Carrier, J., Bastien, C., and Godbout, R. (2020). Sleep and circadian rhythm in response to the COVID-19 pandemic. Canad. J. Public Health 111, 654-657. doi: 10.17269/s41997-020-00382-7

Morin, L. P. (2013). Neuroanatomy of the extended circadian rhythm system. Exp. Neurol. 243, 4-20. doi: 10.1016/j.expneurol.2012.06.026

Morin, L. P., and Studholme, K. M. (2014). Retinofugal projections in the mouse. J. Comp. Neurol. 522, 3733-3753. doi: 10.1002/cne.23635

Nair, S. G., Smirnov, D. S., Estrabrook, M. M., Chisholm, A. D., Silva, P. R., and Neumaier, J. F. (2021). Effect of chemogenetic inhibition of lateral habenula neuronal activity on cocaine- and food- seeking behaviours in the rat. Addict. Biol. 26:e12865. doi: 10.1111/adb.12865

Neusch, C., Papadopoulos, N., Müller, M., Maletzki, I., Winter, S. M., Hirrlinger, J., et al. (2006). Lack of the Kir4.1 channel subunit abolishes K+ buffering properties of astrocytes in the ventral respiratory group: impact on extracellular K+ regulation. J. Neurophysiol. 95, 1843-1852. doi: 10.1152/jn.00996.2005

Newman, E. A. (1993). Inward-rectifying potassium channels in retinal glial (Muller) cells. J. Neurosci. 13, 3333-3345. doi: 10.1523/JNEUROSCI.13-08-03333.1993

Nuno-Perez, A., Trusel, M., Lalive, A. L., Congiu, M., Gastaldo, D., Tchenio, A., et al. (2021). Stress undermines reward-guided cognitive performance through synaptic depression in the lateral habenula. Neuron 109, 947-956. doi: 10.1016/j.neuron.2021.01.008

Nwaobi, S. E., Cuddapah, V. A., Patterson, K. C., Randolph, A. C., and Olsen, M. L. (2016). The role of glial-specific Kir4.1 in normal and pathological states of the CNS. Acta Neuropathl. 132, 1-21. doi: 10.1007/s00401-016-1553-1

Olejniczak, I., Ripperger, J. A., Sandrelli, F., Schnell, A., Mansencal-Strittmatter, L., Wendrich, K., et al. (2021). Light affects behavioral despair involving the clock gene Period 1. PLOS Genetics 17:e1009625. doi: 10.1371/journal.pgen.1009625

Omelchenko, N., Bell, R., and Sesack, S. R. (2009). Lateral habenula projections to dopamine and GABA neurons in the rat ventral tegmental area. Euro. J. Neurosci. 30, 1239-1250. doi: 10.1111/j.1460-9568.2009. 06924.x

Paolucci, E. M., Loukov, D., Bowdish, D. M. E., and Heisz, J. J. (2018). Exercise reduces depression and inflammation but intensity matters. Biol. Psychiatry 133, 79-84. doi: 10.1016/j.biopsycho.2018.01.015

Park, H., Cheon, M., Kim, S., and Chung, C. (2017). Temporal variations in presynaptic release probability in the lateral habenula. Sci. Rep. 7:40866. doi: $10.1038 /$ srep 40866

Partch, C. L., Green, C. B., and Takahashi, J. S. (2014). Molecular architecture of the mammalian circadian clock. Trends Cell Biol. 24, 90-99. doi: $10.1016 /$ j.tcb.2013.07.002

Partridge, B., Lucke, J., and Hall, W. (2012). Public attitudes towards the acceptability of using drugs to treat depression and ADHD. Austr. N. Zeal. J. Psychiatry 46, 958-965. doi: 10.1177/0004867412450755

Paul, M. J., Indic, P., and Schwartz, W. J. (2011). A role for the habenula in the regulation of locomotor activity cycles. Euro. J. Neurosci. 34, 478-488. doi: 10.1111/j.1460-9568.2011.07762.x

Pjerk, E., Friedrich, M.-E., Cambioli, L., Dold, M., Jager, F., Komorowski, A. et al. (2020). The efficacy of light therapy in the treatment of seasonal affective disorder: a meta-analysis of randomized controlled trials. Psychother. Psychosom. 89, 17-24. doi: 10.1159/000502891

Poller, W. C., Madai, V. I., Bernard, R., Laube, G., and Veh, R. W. (2013). A glutamatergic projection from the lateral hypothalamus targets VTAprojecting neurons in the lateral habenula of the rat. Brain Res. 1507, 45-60. doi: 10.1016/j.brainres.2013.01.029 
Power, A., Hughes, A. T. L., Samuels, R. E., and Piggins, H. D. (2010). Rhythm-promoting actions of exercise in mice with deficient neuropeptide signaling. J. Biol. Rhythms 25, 235-246. doi: 10.1177/07487304103 74446

Priest, R. G., Vize, C., Roberts, A., Roberts, M., and Tylee, A. (1996). Lay people's attitudes to treatment of depression: results of opinion poll for Defeat Depression Campaign just before its launch. BMJ 313, 858-859. doi: 10.1136/bmj.313.7061.858

Qu, T., Dong, K., Sugioka, K., and Yamadori, T. (1996). Demonstration of direct input from the retina to the lateral habenular nucleus in the albino rat. Brain Res. 709, 251-258. doi: 10.1016/0006-8993(95)01306-7

Redlin, U. (2001). Neural basis and biological function of masking by light in mammals: suppression of melatonin and locomotor activity. Chronobiol. Int. 18, 737-758. doi: 10.1081/CBI-100107511

Richardson, K. A., and Aston-Jones, G. (2012). Lateral hypothalamic orexin/hypocretin neurons that project to ventral tegmental area are differentially activated with morphine preference. J. Neurosci. 32, 3809-3817. doi: 10.1523/JNEUROSCI.3917-11.2012

Rigney, N., Beaumont, R., and Petrulis, A. (2020). Sex differences in vasopressin la receptor regulation of social communication within the lateral habenula and dorsal raphe of mice. Hormones Behav. 121:104715. doi: 10.1016/j.yhbeh.2020.104715

Rivas-Garajales, A. M., Salas, R., Robinson, M. E., Qi, K., Murrough, J. W., and Mathew, S. J. (2021). Habenula connectivity and intravenous ketamine in treatment-resistant depression. Int. J. Neuropsychopharmacol. 24, 383-391. doi: 10.1093/ijnp/pyaa089

Robbers, Y., Tersteeg, M. M. H., Meijer, J. H., and Coomans, C. P. (2021). Group housing and social dominance hierarchy affect circadian activity patterns in mice. R. Soc. Open Sci. 8:201985. doi: 10.1098/rsos.201985

Rosenwasser, A. M., Pelchat, R. J., and Adler, N. T. (1984). Memory for feeding time: Possible dependence on coupled circadian oscillators. Physiol. Behav. 32, 25-30. doi: 10.1016/0031-9384(84)90064-7

Rusting, C. L., and Larsen, R. J. (1998). Diurnal patterns of unpleasant mood: associations with neuroticism, depression, and anxiety. J. Person. 66, 85-103. doi: 10.1111/1467-6494.00004

Sakhi, K., Belle, M. D. C., Gossan, N., Delagrange, P., and Piggins, H. D. (2014a). Daily variation in the electrophysiological activity of mouse medial habenula neurones. J. Physiol. 592, 587-603. doi: 10.1113/jphysiol.2013.263319

Sakhi, K., Wegner, S., Belle, M. D. C., Howarth, M., Delagrange, P., Brown, T. M., et al. (2014b). Intrinsic and extrinsic cues regulate the daily profile of mouse lateral habenula neuronal activity. J. Physiol. 592, 5025-5045. doi: 10.1113/jphysiol.2014.280065

Sartorius, A., and Henn, F. A. (2007). Deep brain stimulation of the lateral habenula in treatment resistant major depression. Med. Hypotheses 69, 1305-1308. doi: 10.1016/j.mehy.2007.03.021

Sartorius, A., Kiening, K. L., Kirsch, P., Von Gall, C. C., Haberkorn, U., Unterberg, A. W., et al. (2010). Remission of major depression under deep brain stimulation of the lateral habenula in a therapy-refractory patient. Biol. Psychiatry 67, e9-e11. doi: 10.1016/j.biopsych.2009.08.027

Schuch, F. B., and Stubbs, B. (2019). The role of exercise in preventing and treating depression. Curr. Sports Med. Rep. 18, 299-304. doi: 10.1249/JSR.0000000000000620

Sego, C., Goncalves, L., Lima, L., Furigo, I. C., Donato Jr, J., and Metzger, M. (2014). Lateral habenula and the rostromedial tegmental nucleus innervate neurochemically distinct subdivisions of the dorsal raphe nucleus in the rat. J. Comp. Neurol. 522, 1454-1484. doi: 10.1002/ cne. 23533

Seo, J.-S., Zhong, P., Liu, A., Yan, Z., and Greengard, P. (2018). Elevation of p11 in lateral habenula mediates depressionlike behavior. Mol. Psychiatry 23, 1113-1119. doi: 10.1038/mp. 2017.96

Shabel, S. J., Proulx, C. D., Piriz, J., and Malinow, R. (2014). GABA/glutamate corelease controls habenula output and is modified by antidepressant treatment. Science 345, 1494-1498. doi: 10.1126/science. 1250469

Shabel, S. J., Proulx, C. D., Trias, A., Murphy, R. T., and Malinow, R. (2012). Input to the lateral habenula from the basal ganglia is excitatory, aversive and suppressed by serotonin. Neuron 74, 475-481. doi: 10.1016/j.neuron.2012.02.037
Shabel, S. J., Wang, C., Monk, B., Aronson, S., and Malinow, R. (2019). Stress transforms lateral habenula reward responses into punishment signals. Proc. Natl. Acad. Sci. U.S.A. 116, 12488-12493. doi: 10.1073/pnas.1903334116

Shieh, K. R. (2003). Distribution of the rhythm-related genes rPERIOD1, rPERIOD2 and rCLOCK in the rat brain. Neuroscience 118, 831-843. doi: 10.1016/S0306-4522(03)00004-6

Sidor, M. M., Spencer, S. M., Dzirasa, K., Parekh, P. K., Tye, K. M., Warden, M. R., et al. (2016). Daytime spikes in dopaminergic activity drive rapid mood-cycling in mice. Mol. Psychiatry 20, 1406-1419. doi: 10.1038/mp.2014.167

Smagula, S. F., Capps, C. S., and Krafty, R. T. (2021). Evaluating the timing of differences in activity related to depression symptoms across adulthood in the United States. J. Affect. Disord. 284, 64-68. doi: 10.1016/j.jad.2021.01.069

Smith, R. J., Vento, P. J., Chao, Y. S., Good, C. H., and Jhou, T. C. (2019). Gene expression and neurochemical characterization of the rostromedial tegmental nucleus in rats and mice. Brain Struct. Funct. 224, 219-238. doi: 10.1007/s00429-018-1761-7

Stamatakis, A. M., Jennings, J. H., Ung, R. L., Blair, G. A., Weinberg, R. J., Neve, R. L., et al. (2013). A unique population of ventral tegmental area neurons inhibits the lateral habenula to promote reward. Neuron 80, 1039-1053. doi: 10.1016/j.neuron.2013.08.023

Stamatakis, A. M., and Stuber, G. D. (2012). Activation of lateral habenula inputs to the ventral midbrain promotes behavioral avoidance. Nat. Neurosci. 24, 1105-1107. doi: 10.1038/nn.3145

Stamatkis, A. M., Swieten, M. V., Basiri, M. L., Blair, G. A., Kanatak, P., and Stuber, G. D. (2016). Lateral hypothalamic area glutamatergic neurons and their projections to the lateral habenula regulate feeding and reward. J. Neurosci. 36, 301-311. doi: 10.1523/JNEUROSCI.1202-15.2016

Stephenson-Jones, M., Yu, K., Ahrens, S., Tucciarone, J. M., Van Huijstee, A. N., Mejia, L. A., et al. (2016). A basal ganglia circuit for evaluating action outcomes. Nature 539, 289-293. doi: 10.1038/nature19845

Stern, W. C., Johnson, A., Bonzino, J. D., and Morgane, P. J. (1979). Effects of electrical stimulation of the lateral habenula on single-unit activity of raphe neurons. Exp. Neurol. 65, 326-342. doi: 10.1016/0014-4886(79)90102-X

Stopper, C. M., Tse, M. T. L., Montes, D. R., Wiedman, C. R., and Floresco, S. B. (2014). Overriding phasic dopamine signals redirects action selection during risk/reward decision making. Neuron 84, 177-189. doi: 10.1016/j.neuron.2014.08.033

Stow, L. R., Richards, J., Cheng, K.-Y., Lynch, I. J., Jeffers, L. A., Greenlee, M. M., et al. (2012). The circadian protein period 1 contributes to blood pressure control and coordinately regulates renal sodium transport genes. Hypertension 59, 1151-1156. doi: 10.1161/HYPERTENSIONAHA.112.190892

Sutherland, R. J. (1982). The dorsal diencephalic conduction system: a review of the anatomy and functions of the habenular complex. Neurosci. Biobehav. Rev. 6, 1-13. doi: 10.1016/0149-7634(82)90003-3

Swanson, L. M., Burgess, H. J., Huntley, E. D., Bertram, H., Mooney, A., Zollars, J., et al. (2017). Relationships between circadian measures, depression, and response to antidepressant treatment: a preliminary investigation. Psychiatry Res. 252, 262-269. doi: 10.1016/j.psychres.2017.03.010

Szonyi, A., Zicho, K., Barth, A. M., Gonczi, R. T., Schlingloff, D., Torok, B., et al. (2019). Median raphe controls acquisition of negative experience in the mouse. Science 366:aay8746. doi: 10.1126/science.aay8746

Ter Horst, G. J., and Luiten, P. G. M. (1986). The projections of the dorsomedial hypothalamic nucleus in the rat. Brain Res. Bull. 16, 231-248. doi: 10.1016/0361-9230(86)90038-9

Timothy, J. W. S., Klas, N., Sanghani, H. R., Al-Mansouri, T., Hughes, A. T. L., Kirshenbaum, G. S., et al. (2018). Circadian disruptions in the myshkin mouse model of mania are independent of deficits in suprachiasmatic molecular clock function. Biol. Psychiatry 84, 827-837. doi: 10.1016/j.biopsych.2017.04.018

Tolles-Correia, D., Saravia, S., and Goncalves, J. (2018). Mental disorder-the need for an accurate definition. Front. Psychiatry 9:64. doi: 10.3389/fpsyt.2018.00064

Tong, X., Ao, Y., Faas, G. C., Nwaobi, S. E., Xu, J., Haustein, M. D., et al. (2014). Astrocyte Kir4.1 ion channel deficits contribute to neuronal dysfunction in Huntington's disease model mice. Nat. Neurosci. 17, 694-703. doi: $10.1038 / \mathrm{nn} .3691$

Tooley, J., Marconi, L., Alipio, J. B., Matikainen-Ankey, B., Georgiou, P., Kravitz, A., et al. (2018). Glutamatergic ventral pallidal neurons modulate activity of the habenula-tegmental circuitry and constrain reward seeking. Biol. Psychiatry 83, 1012-1023. doi: 10.1016/j.biopsych.2018.01.003 
Valentinova, K., Tchenio, A., Trusel, M., Clerke, J. A., Lalive, A. L., Tzanoulinou, S., et al. (2019). Morphine withdrawal recruits lateral habenula cytokine signaling to reduce synaptic excitation and sociability. Nat. Neurosci. 22, 1053-1056. doi: 10.1038/s41593-019-0421-4

Vermeulen, E., Stronks, K., Snijder, M. B., Schene, A. H., Lok, A., De Vries, J. H., et al. (2017). A combined high-sugar and high-saturated-fat dietary pattern is associated with more depressive symptoms in a multi-ethnic population: the HELIUS (Healthy Life in an Urban Setting) study. Public Health Nutr. 20, 2374-2382. doi: 10.1017/S1368980017001550

Wagner, F., French, L., and Veh, R. W. (2016). Transcriptomic-anatomic analysis of the mouse habenula uncovers a high molecular heterogeneity among neurons in the lateral complex, while gene expression in the medial complex largely obeys subnuclear boundaries. Brain Struct. Funct. 221, 39-58. doi: 10.1007/s00429-014-0891-9

Wagner, F., Stroh, T., and Veh, R. W. (2014). Correlating habenular subnuclei in rat and mouse by using topographic, morphological and cytochemical criteria. J. Comp. Neurol. 522, 2650-2662. doi: 10.1002/cne.23554

Wang, D., Li, A., Dong, K., Li, H., Guo, Y., Zhang, X., et al. (2021). Lateral hypothalamus orexinergic inputs to lateral habenula modulate maladaptation after social defeat stress. Neurobiol. Stress 14:100298. doi: 10.1016/j.ynstr.2021.100298

Webb, I. C., Baltazar, R. M., Wang, X., Pitchers, K. K., Coolen, L. M., and Lehman, M. N. (2009). Diurnal variations in natural and drug reward, mesolimbic tyrosine hydroxylase, and clock gene expression in the male rat. J. Biol. Rhythms 24, 465-476. doi: 10.1177/0748730409346657

Weiss, T., and Veh, R. W. (2011). Morphological and electrophysiological characteristics of neurons within identified subnuclei of the lateral habenula in rat brain slices. Neuroscience 172, 74-93. doi: 10.1016/j.neuroscience.2010.10.047

Wirz-Justice, A. (2008). Diurnal variation of depressive symptoms. Dial. Clin. Neurosci. 10, 337-343. doi: 10.31887/DCNS.2008.10.3/awjustice

Wulff, K., Gatti, S., Wettstein, J. G., and Foster, R. G. (2010). Sleep and circadian rhythm disruption in psychiatric and neurodegenerative disease. Nat. Rev. Neurosci. 11, 589-599. doi: 10.1038/nrn2868

Yan, L., and Silver, R. (2002). Differential induction and localization of mPer1 and mPer2 during advancing and delaying phase shifts. Euro. J. Neurosci. 16, 1531-1540. doi: 10.1046/j.1460-9568.2002.02224.X

Yang, Y., Cui, Y., Sang, K., Dong, Y., Ni, Z., Ma, S., et al. (2018a). Ketamine blocks bursting in the lateral habenula to rapidly relieve depression. Nature 554, 317-322. doi: 10.1038/nature25509

Yang, Y., Wang, H., Hu, J., and Hailan, H. (2018b). Lateral habenula in the pathophysiology of depression. Curr. Opin. Neurobiol. 48, 90-96. doi: 10.1016/j.conb.2017.10.024

Yeoh, J. W., James, M. H., Adams, C. D., Bains, J. S., Sakuri, T., Aston-Jones, G., et al. (2019). Activation of lateral hypothalamic group III metabotropic glutamate receptors suppresses cocaine-seeking following abstinence and normalizes drug-associated increases in excitatory drive to orexin/hypocretin cells. Neuropharmacology 154, 22-33. doi: 10.1016/j.neuropharm.2018. 09.033
Zanos, P., and Gould, T. D. (2018). Mechanisms of ketamine action as an antidepressant. Mol. Psychiatry 23, 801-811. doi: 10.1038/mp. 2017.255

Zerssen, D. V., Bathelmes, H., Dirlich, G., Doerr, P., Emrich, H. M., Von Lindern, L., et al. (1985). Circadian rhythms in endogenous depression. Psychiatry Res. 16, 51-63. doi: 10.1016/0165-1781(85)90028-9

Zhang, C., Truong, K. K., and Zhou, Q.-Y. (2009). Efferent projections of prokineticin 2 expressing neurones in the mouse suprachiasmatic nucleus. PLoS ONE 4:e7151. doi: 10.1371/journal.pone.0007151

Zhang, J., Tan, L., Ren, Y., Liang, J., Lin, R., Feng, Q., et al. (2016). Presynaptic excitation via GABAB receptors in habenula cholinergic neurons regulates fear memory expression. Cell 166, 716-728. doi: 10.1016/j.cell.2016.06.026

Zhao, H., and Rusak, B. (2005). Circadian firing-rat rhythms and light responses of rat habenular nuclei in vivo and in vitro. Neuroscience 132, 519-528. doi: 10.1016/j.neuroscience.2005.01.012

Zhou, Q.-Y., and Cheng, M. Y. (2005). Prokineticin 2 and circadian clock output. FEBS J. 272, 5703-5709. doi: 10.1111/j.1742-4658.2005.04984.x

Zhu, Y., Qi, S., Zhang, B., He, D., and Teng, Y. (2019). Connectomebased biomarkers predict subclinical depression and identify abnormal brain connections with the lateral habenula and thalamus. Front. Psychiatry 10:371. doi: $10.3389 /$ fpsyt.2019.00371

Zhuo, C., Tian, H., Li, G., Chen, M., Jiang, D., Lin, X., et al. (2019). Effects of ketamine on circadian rhythm and synaptic homeostasis in patients with treatment-resistant depression: a protocol for mechanistic studies of its rapid and sustained antidepressant actions in humans. Brain Behav. 9:e01423. doi: 10.1002/brb3.1423

Zuo, W., Zhang, Y., Xie, G., Gregor, D., Bekker, A., and Ye, J.-H. (2016). Serotonin stimulates lateral habenula via activation of the post-synaptic serotonin $2 / 3$ receptors and transient receptor potential channels Neuropharmacology 101, 449-459. doi: 10.1016/j.neuropharm.2015.10.012

Conflict of Interest: The authors declare that the research was conducted in the absence of any commercial or financial relationships that could be construed as a potential conflict of interest.

Publisher's Note: All claims expressed in this article are solely those of the authors and do not necessarily represent those of their affiliated organizations, or those of the publisher, the editors and the reviewers. Any product that may be evaluated in this article, or claim that may be made by its manufacturer, is not guaranteed or endorsed by the publisher.

Copyright (c) 2022 Young, Lyons and Piggins. This is an open-access article distributed under the terms of the Creative Commons Attribution License (CC BY). The use, distribution or reproduction in other forums is permitted, provided the original author(s) and the copyright owner(s) are credited and that the original publication in this journal is cited, in accordance with accepted academic practice. No use, distribution or reproduction is permitted which does not comply with these terms. 